\title{
Climatological Ertel's potential-vorticity flux and mean meridional circulation in the extratropical troposphere - lower stratosphere
}

\author{
J. Bartels ${ }^{2}$, D. Peters ${ }^{1}$, G. Schmitz ${ }^{1}$ \\ ${ }^{1}$ Institut für Atmosphärenphysik an der Universität Rostock, Schloßstr. 6, D-18225 Ostseebad Kühlungsborn, Germany \\ ${ }^{2}$ Niedersächsisches Landesamt für Bodenforschung - Geowissenschaftliche Gemeinschaftsaufgaben, Postfach 510153 , \\ D-30631 Hannover, Germany
}

Received: 4 March 1997 / Revised: 25 August 1997 / Accepted: 5 September 1997

\begin{abstract}
We investigated to what extent the isentropic, non-geostrophic formulation of zonally averaged circulation derived for stratospheric conditions is applicable to climatological transport in the extratropical troposphere and lower stratosphere. The study is based on 10 years of daily data of ECMWF analysis and on the ECHAM3 climate model of the German Climate Computing Centre. The main result is a scalar isentropic mixing coefficient, $K_{y y}$, and a mean meridional transport circulation consistently derived from the same data base. For both data sources, isentropic mean meridional circulation is derived from horizontal mass flow rate for 4 representative months. Alternatively, a mean meridional circulation is calculated from total diabatic heating rates of the ECHAM3 model. It is shown that only the latter is in good agreement with the ECMWF mean meridional circulation. Isentropic analysis also comprises the seasonal cycle of the climatological meridional gradient and flux of Ertel's potential vorticity (PV). Application of Tung's flux-gradient relation yields that for all seasons $K_{y y}$ is positive in heightlatitude regions where statistical significance is reached. Large $K_{y y}$ values, marking regions of more efficient mixing, have been found in the subtropical vertical band of weak westerly wind and in mid-latitudes in regions of upward-propagating baroclinic wave activity in the middle and upper troposphere. Based on the ECMWF data and results of baroclinic-wave behaviour, strong indications are presented that positive zonally averaged PV flux polewards of the jet core in the $\mathrm{NH}$ is strengthened by stationary waves and nonlinear effects. Reduced eddy transport is apparent in winter and spring slightly below the subtropical tropopause jet. The seasonal cycle of $K_{y y}$ from ECHAM3 data is to a great extent in agreement with the result based on ECMWF analysis. In the model, reduced interannual variability enlarges the height-latitude range where sign of $K_{y y}$ is significant.
\end{abstract}

Correspondence to: Dr. Dieter Peters. e-mail: peters@iap-kborn.de
Key words Meteorology and atmospheric dynamics . Climatology $\cdot$ General circulation · Middle atmosphere

\section{Introduction}

The global climatological distribution of an atmospheric tracer is determined more by dynamical transport the longer its chemical lifetime. The zonally averaged distribution of long-living, quasi-conservative tracers is influenced by transport of stationary and transient waves. In a climatological time-scale, zonal mean tracer distribution can be determined in an effective way with the help of zonally averaged transport (2D) models. The contribution to zonal mean transport which is not resolved in such models comes from longitudinal correlations of large-scale eddies. It has to be parameterized by zonally averaged quantities.

Two-dimensional models become an indispensable part of the hierarchy of transport models if a large number of chemical species, coupled with a complex system of chemical reactions, has to be considered, e.g. for the interpretation of observed zonal mean ozone distribution and trend (WMO, 1995).

At the moment we notice an evolution of these transport-chemistry models characterized by an improvement in the chemical part and by the extension of the data base for additional natural and anthropogenic sources. On the other hand, experiments with idealized $\mathrm{N}_{2} \mathrm{O}$-like tracers and prescribed latitude and time-independent photochemical loss rate have shown considerable differences between the predictions of a series of transport-chemistry models for the latitudeheight distribution of such long living tracers (Prather und Remsberg, 1993). These differences have their origin in a different representation of dynamical transport. By presentation of a consistent climatological mean meridional circulation and an exchange parameter representing the effect of large-scale eddies in the 
troposphere and lower stratosphere, this work tries to contribute towards an improvement.

The partition of zonally averaged transport into a zonal mean meridional mass circulation and an eddy contribution depends on the choice of the vertical coordinate. Both in the transformed Eulerian mean (TEM) (Andrews and McIntyre, 1976) and in the isentropic mean (Andrews, 1983; Tung, 1986), the meridional mass circulation already has a cell structure which is similar to the Brewer-Dobson circulation. The additional zonally averaged tracer transport by transient eddies is usually related to the gradient of zonally averaged tracer concentration via a $2 \times 2$ matrix of diffusion coefficients, $\boldsymbol{K}$. $\boldsymbol{K}$ can be decomposed into two components (e.g. Plumb, 1979; Pyle and Rogers, 1980; Tung, 1982). In linear approximation the dynamic component describes mixing. The second component, usually denoted as "chemical", in weakly non-linear approximation describes the effect of scale-independent dissipative processes like radiational damping and photochemical decay. Both components of $\boldsymbol{K}$ can be calculated from the longitudinal distribution of Lagrangian parcel displacements and their correlation, which are, however, not available in most cases.

The dynamic component of $\boldsymbol{K}$ quantifies a transport process which is the same for every conservative tracer. That means it can be determined from the temporal evolution of the spatial distribution of an arbitrary conservative tracer. With respect to the horizontal matrix component, $K_{y y}$, Juckes (1989) has demonstrated that the dynamically active tracer "potential vorticity" behaves like a "normal" passive tracer with a small and constant chemical loss rate. The unique advantage of potential vorticity is that its global distribution can be calculated from atmospheric standard quantities. Schmitz and Dethloff (1984) discussed flux-gradient parameterization of quasi-geostrophic vorticity flux in pressure coordinates obtained from climatological data for the extratropical northern winter troposphere and found upgradient flux in the vicinity of the tropopause.

Newman et al. (1988) determined seasonal mixing coefficients from fluxes and gradients of quasi-geostrophic potential vorticity based on 4 years of NMCanalysis geopotential height and temperature data for troposphere and stratosphere. Plumb and Mahlman (1987) obtained seasonal $\boldsymbol{K}$ consistent to a generalized transport circulation, which is equivalent to TEM residual circulation if diabatic heating can be neglected. 3D transport experiments with the GFDL general circulation model (GCM) gave fluxes of two tracers with orthogonal concentration gradients up to a height of $10 \mathrm{hPa}$. This was the basis of an independent determination of seasonal values of all four matrix elements of $\boldsymbol{K}$. By 2D transport calculations with these transport parameters, Plumb and Mahlman demonstrated the ability of a 2D model to reproduce zonally averaged tracer distributions of equivalent 3D-model experiments.

Yang et al. (1990) and Sassi et al. (1990) used observed stratospheric temperature data to deduce flux of Ertel's potential vorticity (PV) from the zonally averaged angular momentum balance, according to the isentropic, non-geostrophic angular momentum equation (Tung, 1986). Their scalar $K_{y y}$, derived from the isentropic fluxgradient relation for PV (Tung, 1986), gives a measure of mixing efficiency caused by transient eddies.

The aim of this work is the extension of Tung's method to the middle and upper troposphere. The investigation is based on ECMWF-analysis data from 1984 to 1993 and on results from experiments with the ECHAM3 GCM. Both data sets enable the consistent determination of mean meridional transport circulation and $K_{y y}$ in their seasonal dependence. In contrast to Yang et al. (1990) and Sassi et al. (1990), who had to apply the zonally averaged angular momentum balance equation, PV flux can be calculated directly from the local deviations from zonal average. Comparison of the results from ECMWF-analysis data and ECHAM3model data gives an estimate of the performance of the GCM with respect to zonally averaged tracer transport.

The outline of the work is as follows. In Sect. 2 the expressions for the mean meridional circulation and the flux-gradient relation in isentropic coordinates are given. In Sect. 3 data sources and data processing are described in detail. In Sects. 4.1 and 4.2 results derived from the ECMWF analysis data are shown for mean meridional circulation, meridional PV flux by transient eddies, PV gradient and eddy mixing coefficient. The corresponding results from the GCM data are presented in Sects. 4.3 and 4.4 . In Sect. 5 results are discussed and in Sect. 6 a summary and conclusions are given.

\section{Zonally averaged equations and parameterization}

In this work the eddy flux parameterization scheme of Tung (1986) is applied. Potential temperature, $\Theta$, is used as vertical coordinate. The zonally averaged transport equation for the volume mixing ratio, $X$, of a conservative tracer weighted by the density, $\rho_{\Theta}$, appropriate in $\Theta$-coordinates, reads

$$
\begin{aligned}
& {\left[\overline{\rho_{\Theta}} \overline{\bar{X}}\right]_{t}+[\bar{V} \overline{\bar{X}}]_{y}+[\bar{W} \overline{\bar{X}}]_{\Theta}} \\
& \quad=-\left[\overline{\rho_{\Theta} v^{*} X^{*} \cos \varphi}\right]_{y}-\left[\overline{\rho_{\Theta} \Theta^{*} X^{*}}\right]_{\Theta} .
\end{aligned}
$$

Indices at square brackets denote partial derivatives. Density-weighted zonal averaging is defined by

$\overline{\bar{X}}=\frac{\overline{\rho_{\Theta} X}}{\overline{\rho_{\Theta}}}$ and $X^{*}=X-\overline{\bar{X}}$.

Density in $\Theta$-coordinates is defined as

$\rho_{\Theta}=\rho \frac{\partial z}{\partial \Theta}=-\frac{1}{g} \frac{\partial p}{\partial \Theta}$.

Single overbars represent the usual zonal average along isentropes; $t$ is time and $p$ pressure. Latitudinal coordinate is $y=a \cdot \sin \varphi ; a$ means the earth's radius; $z$ is the geometrical height, $v$ and $\dot{\Theta}$ are the meridional and vertical wind velocities, $V$ and $W$ are the respective mass flow rates, defined by 
$V=\rho_{\Theta} v \cos \varphi$,

$W=\rho_{\Theta} \frac{\mathrm{d} \Theta}{\mathrm{d} t}=\rho_{\Theta} \frac{\Theta}{T} Q$.

$Q$ is the diabatic heating rate. The zonally averaged continuity equation reads

$\left[\overline{\rho_{\Theta}}\right]_{t}+[\bar{V}]_{y}+[\bar{W}]_{\Theta}=0$

With the steady-state assumption the isentropic mass streamfunction is defined according to Townsend and Johnson (1985) by

$\Psi_{v}(\varphi, \Theta)=-2 \pi a \int_{\Theta_{\mathrm{top}}}^{\Theta} \bar{V} \mathrm{~d} \Theta$

if $\bar{V}$ is known and the boundary condition of vanishing $\bar{W}$ and $\Psi$ is applied at the top $\Theta$-level. The subscript denotes the quantity $\Psi$ is derived from. If $\bar{W}(Q)$ is known and $\bar{V}$ and therefore $\Psi$ are assumed to vanish at the poles, $\Psi$ can be obtained from

$\Psi_{Q}(\varphi, \Theta)=2 \pi a^{2} \int_{-90^{\circ}}^{\varphi} \cos \varphi \bar{W} \mathrm{~d} \varphi$.

Since the boundary condition of Eq. (6a) is somewhat artificial in the lower stratosphere, Eq. (6b) should be preferred if $Q$ is available. By combination of Eqs. (4), (6a) and (6b), $\bar{V}$ can be obtained from $\bar{W}$ or $Q$, and vice versa. Application of vertical coordinate $\Theta$ involves the problem that in mid-latitudes isosurfaces steeply intersect the ground. An implication in the lower troposphere is that $\Theta_{\text {isentrope }}<\Theta_{\text {surface }}$ for parts of the isentropic averaging path. The ratio of those parts increases with decreasing height. Those grounded isentropes are treated with the procedure of Lorenz (1955) and Andrews (1983) [see also Juckes et al. (1994) and Townsend and Johnson (1985)]. By setting $\rho_{\Theta}$ equal to zero if $\Theta_{\text {isentrope }}<\Theta_{\text {surface }}$, it is achieved that the density weighted mean [Eq. (2)] contains no contribution from such a region.

For 2D calculations eddy flux terms on the righthand side of Eq. (1) have to be expressed by zonally averaged quantities. Tung (1986) has derived a relation for the horizontal eddy flux term in Eq. (1) from linearization and scale analysis of the perturbation form of Ertel's PV equation. Generalization for any conservative tracer leads to:

$$
\begin{aligned}
\overline{\rho_{\Theta} v^{*} X^{*} \cos \varphi}= & -\overline{\rho_{\Theta} v^{*} \eta^{*} \cos ^{2} \varphi}[\overline{\bar{X}}]_{y} \\
& -\overline{\rho_{\Theta} v^{*} \phi^{*} \cos \varphi}[\overline{\bar{X}}]_{\Theta} \\
= & -\overline{\rho_{\Theta}} K_{y y} \cos ^{2} \varphi[\overline{\bar{X}}]_{y} \\
& -\overline{\rho_{\Theta}} K_{y \Theta} \cos \varphi[\overline{\bar{X}}]_{\Theta},
\end{aligned}
$$

with

$$
\overline{\rho_{\Theta}} K_{y y}=\overline{\rho_{\Theta} v^{*} \eta^{*}}=\overline{\rho_{\Theta} \frac{1}{2} \frac{\partial}{\partial t}\left(\eta^{*}\right)^{2}}
$$

and
$\bar{\rho}_{\Theta} K_{y \Theta}=\overline{\rho_{\Theta} v^{*} \phi^{*}}$

$\eta^{*}$ and $\phi^{*}$ are the horizontal and vertical displacements of air parcels from their undisturbed position. Usually, these Lagrangian quantities are not known. Therefore, the eddy terms in Eq. (7), summarized to mixing coefficients, $K_{y y}$ and $K_{y \Theta}$, cannot be calculated directly. For adiabatic processes $\phi^{*}$ vanishes. From the Lagrangian structure of the remaining coefficient $K_{y y}$ in Eq. (7) it becomes clear that in this approximation, transient behaviour causes diffusive horizontal transport.

In the absence of diabatic heating sources Ertel's potential vorticity, $P$, is a conservative quantity, i.e.

$\frac{\mathrm{d}}{\mathrm{d} t} P=\frac{\mathrm{d}}{\mathrm{d} t}\left(\frac{\left.\xi\right|_{\Theta}+f}{\rho_{\Theta}}\right)=0$

$f$ is the Coriolis parameter $\left.\xi\right|_{\Theta}$ and the relative vorticity calculated along $\Theta$-surfaces. For adiabatic motion of air parcels it follows from Eq. (7), that

$\overline{\rho_{\Theta} v^{*} P^{*} \cos \varphi}=-\overline{\rho_{\Theta}} K_{y y} \cos ^{2} \varphi[\overline{\bar{P}}]_{y}$.

Furthermore, for adiabatic processes the northward PV flux [Eq. (9)] is related to the divergence of the EliassenPalm flux, $F$, the eddy forcing term in the zonally averaged angular momentum equation (Andrews, 1983; Tung, 1986), by

$$
\begin{aligned}
\nabla \cdot F & =\frac{\partial}{\partial y} F_{y}+\frac{\partial}{\partial \Theta} F_{\Theta}-\overline{\rho_{\Theta}} \frac{\partial}{\partial t} \overline{\rho_{\Theta}^{\prime} u^{\prime}} \cos \varphi \\
& =\overline{\rho_{\Theta}} \overline{\rho_{\Theta} v^{*} P^{*} \cos \varphi}, \\
F_{y} & =-\overline{u^{\prime}\left(\rho_{\Theta} v\right)^{\prime}} \cos ^{2} \varphi, \\
F_{\Theta} & =\frac{1}{g} \overline{p^{\prime} \frac{\partial}{a \partial \lambda} M^{\prime}},
\end{aligned}
$$

where a prime is defined as deviation from zonal mean. $M$ is the Montgomery streamfunction, defined by $M=c_{p} T+\Phi$. $\Phi$ being the geopotential. Near the ground the non-adiabatic processes are assumed to be strong, so that eddy parameterization on grounded isentropes is not examined.

\section{Data analysis procedure}

\subsection{ECMWF analysis}

The applicability of the isentropic, quasi-adiabatic parameterization scheme [Eq. (9)] in the troposphere was examined based upon a 10-year data set of the ECMWF analysis (in the following referred to as analysis data) from 1984 to 1993. Prior to October 1989 it is available in T63 resolution, and thereafter in T106 resolution. For better comparison with the available ECHAM3 results spectral ECMWF data were transformed to a spatial grid of $6^{\circ}$ horizontal resolution. In the vertical direction data were interpolated linearly in $(\Theta / 285 \mathrm{~K})^{-3,5}$ from pressure to $\Theta$-levels with constant $\Delta \Theta$ of $10 \mathrm{~K}$. Comparison with $5-\mathrm{K}$ resolution has not shown a significant change. 
Based on the parameterization formula Eq. (9), a first methodical evaluation of the data sets with a linear regression formula for $K_{y y}$ (Newman et al., 1988) applied to time-series of daily and monthly averaged flux-gradient data pairs was carried out. The regression formula was divided into a term describing the temporal correlation of transient flux and meridional gradient and a term consisting of the ratio of temporal means of both quantities. It turns out that the contribution of temporal correlation in this time-scale is predominantly negative and only weak compared with the contribution of the temporal means. In such a case of vanishing temporal correlation, the regression coefficient, $K_{y y}$, decreases with increasing gradient variability. This undesirable effect of uncorrelated noise would enlarge the difference between real mean flux and a parameterized flux calculated for a 2D model from a mean gradient and $K_{y y}$. To eliminate this artifact caused by the least-squares fit algorithm, $K_{y y}$ is calculated from the ratio of temporal-averaged monthly mean flux and gradient values according to Eq. (11). This is physically appropriate if we focus on a climatological seasonal $K_{y y}$-cycle for monthly averaged tracer fluxes and regions with sufficiently steep meridional gradients.

$$
K_{y y}(y, \Theta) \cos ^{2} \varphi=-\frac{\sum_{m=1}^{M} \overline{\left\{\rho_{\Theta} v^{*} P^{*}\right\}_{\text {transient }}^{(m)}} \cos ^{2} \varphi}{\sum_{m=1}^{M}\left\{\overline{\rho_{\Theta}} \cos \varphi[\overline{\bar{P}}]_{y}\right\}^{(m)}} .
$$

Curved brackets with superscript $m$ represent monthly means. For January, April, July and October time-series of $M=10$ data pairs of monthly averaged flux and gradient were formed. The flux caused by transient eddies in Eq. (11) is the difference between total and stationary flux

$$
\overline{\left\{\rho_{\Theta} v^{*} P^{*}\right\}_{\text {transient }}^{(m)}}=\overline{\left\{\rho_{\Theta} v^{*} P^{*}\right\}_{\text {total }}^{(m)}}-\overline{\left\{\rho_{\Theta}\right\}\left\{v^{*}\right\}\left\{P^{*}\right\}},
$$

where curved brackets without an index denote a temporal average over the whole data series. With this method statistical error results from the interannual variability only. Confidence interval is calculated for a statistical certainty of $95 \%$. The main drawback is the possible appearance of large relative errors in regions with small climatological PV gradient where parameterization on the basis of zonal mean PV distribution is questionable.

Because $Q$ is not available here, meridional mass streamfunction, $\Psi_{v}$, was calculated from Eq. (6a) with vanishing vertical mass flux at $500 \mathrm{~K}$ as upper boundary condition. Experiments with a systematic downward shift of this upper boundary position yielded no noticeable effect on $\Psi_{v}$ only below $390 \mathrm{~K}$, and so we have to restrict our considerations to this region.

\subsection{ECHAM3 experiments}

The model data basis consists of GCM results of the T21 and T42 versions of the ECHAM3 model of the German
Climate Computing Centre in Hamburg (Roeckner et al., 1992; GCCC, 1993). It comprises the height region from the ground up to $10 \mathrm{hPa}$. The data set of the GCM was treated in analogy to the analysis data. The following GCM experiments were used:

1. ECHAM3 experiments in T42 resolution (transformed to a $5.6^{\circ}$ grid) over 6 years. The climatological annual cycle of the sea-surface temperature (SST) which is used in the Atmospheric Model Intercomparison Project (AMIP I, 1995) was repeated every year. These experiments without externally forced interannual variability were chosen to reduce statistical variability in estimates of $K_{y y}$. The output of these experiments does not include diabatic heating rates.

2. Experiments in T21 resolution $\left(\approx 5.6^{\circ}\right)$ over 6 years with ECHAM3 standard climatological annual cycle of SST (Roeckner et al., 1992). This data set includes the total diabatic heating rate (GCCC, 1993).

T42 experiments were used to calculate $K_{y y}$ and the mean meridional streamfunction, $\Psi_{v}$, with upper boundary at $500 \mathrm{~K}$. The meridional stream function, $\Psi_{Q}$ was calculated with T21 data for the same height region. An estimation of $\bar{V}$ directly calculated from meridional wind velocity and mass density [Eq. (4)] and from $\Psi_{Q}$ [Eq. (6a, b)] allows a comparison of both.

Note that at each latitude there is a minimum $\Theta_{\text {surface }}$ value, $\Theta_{\min }(\varphi)$, along the latitudinal circle. $\Theta_{\min }(\varphi)$ is largest in the tropics and decreases towards the poles. Consequently, at the bottom of a $\Theta-\varphi$ plot of zonally averaged quantities, a white region exists below $\Theta_{\min }(\varphi)$, which is completely below the ground.

\section{Results}

\subsection{Mean meridional circulation from ECMWF analysis}

Here we present the corresponding meridional mass streamfunction, $\Psi_{v}$, for 1 month from every season. In Fig. 1 tropospheric thermal direct circulation cells reaching from the tropics to polar latitudes can be found in varying strength in January (a), April (b), July (c) and October (d). A characteristic feature is the descent between $20^{\circ}$ and $40^{\circ}$ latitude in the upper troposphere which allows the subdivision into a tropical/subtropical branch similar to the Hadley cell in pressure coordinates and a weaker branch from middle to polar latitudes.

Circulation is strongest in the winter hemispheres, where it has a maximum value of $-17 \cdot 10^{10} \mathrm{~kg} \mathrm{~s}^{-1}$ in July in the region of the Hadley branch. The stream function is nearly symmetric in equinoxes with maximum values of $\pm 7 \cdot 10^{10} \mathrm{~kg} \mathrm{~s}^{-1}$ again in the Hadley branch. Circulation in the southern hemisphere (SH) winter (summer) is stronger than in the northern hemisphere $(\mathrm{NH})$ winter (summer). One can clearly see the asymmetric position of the winter cells in respect to the equator. In July the $\mathrm{SH}$ cell is more extended to $\mathrm{NH}$ tropics than its $\mathrm{NH}$ counterpart in January to $\mathrm{SH}$ tropics. Consequently, in the annual mean a northward shift is to be expected. Qualitatively, strongest circula- 

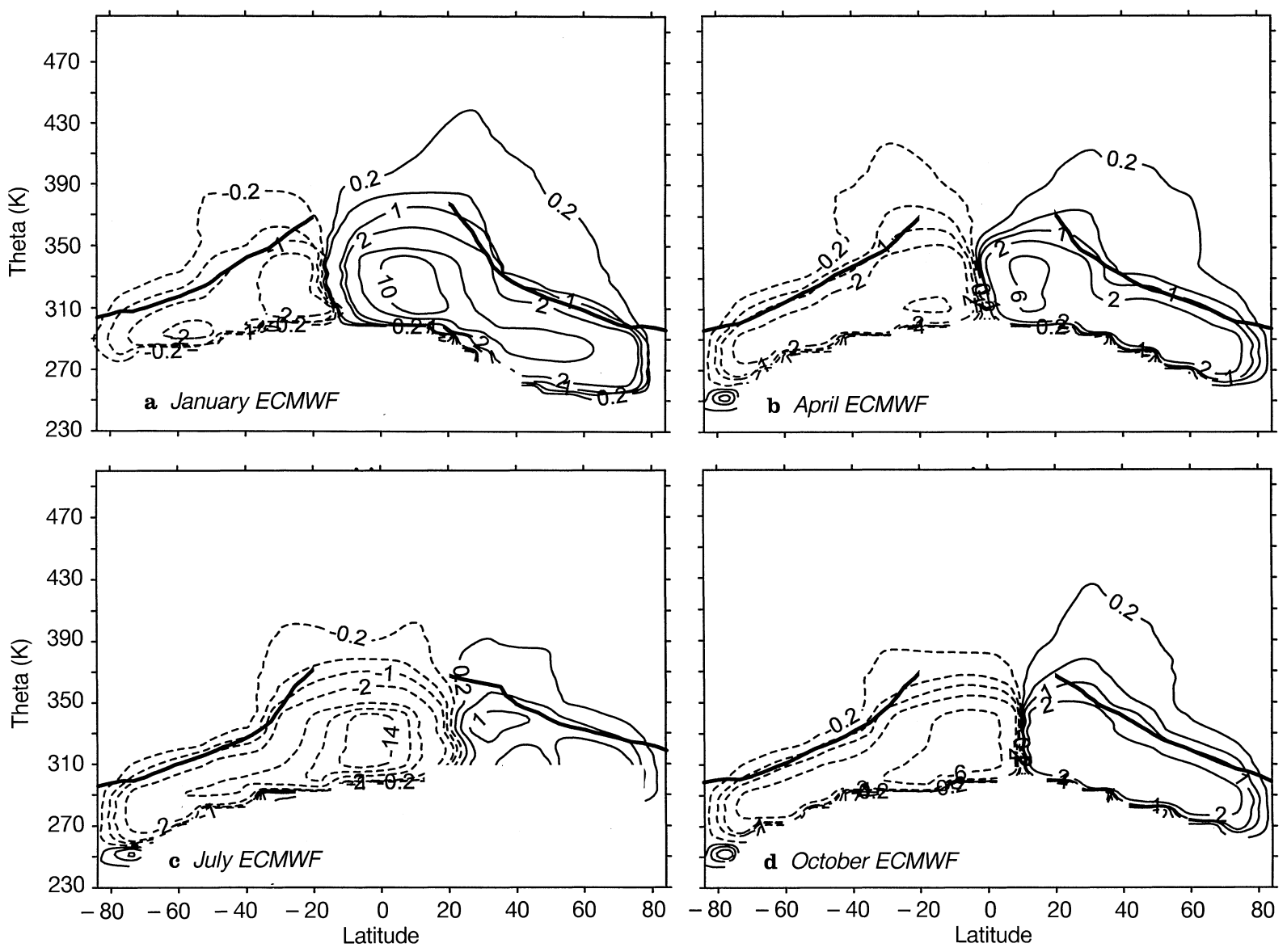

Fig. 1. Isentropic mass streamfunction, $\Psi_{v}$, in $10^{10} \mathrm{~kg} \mathrm{~s}^{-1}$ for 4 months from ECMWF analysis. The contour interval is 0.4 between -1 and 1 , and 4 above and below \pm 2 . Negative contours are dashed.

Thick solid lines mark the zonally averaged dynamical tropopause $\left(\mathrm{PV}=2 \cdot \mathrm{K} \mathrm{m}^{2} \mathrm{~kg}^{-1} \mathrm{~s}^{-1}\right)$

tion in the lower stratosphere is found in NH winter at middle and high latitudes. Note the different contour interval below and above \pm 1 . The thick solid line marks the zonally averaged dynamical tropopause, which is defined here by a constant absolute PV value of $2 \mathrm{~K} \mathrm{~m}^{2} \mathrm{~kg}^{-1} \mathrm{~s}^{-1}$. The definition is only useful polewards of about $20^{\circ}$ because PV values pass zero at the equator. The tropopauses defined in that way practically coincide in $\mathrm{NH}$ and $\mathrm{SH}$ winter, whereas in $\mathrm{NH}$ summer the tropopause is slightly higher than in $\mathrm{SH}$ summer. The tropopauses of the corresponding hemispheres in April and October also coincide. Furthermore, Fig. 1 shows a strong isentropic mass circulation confined to the troposphere in mid-latitudes in all seasons. Note the change of contour distance near the tropopause.

\subsection{Eddy flux parameterization based on ECMWF analysis data}

In this section we focus on the climatological mixing coefficient $K_{y y}(\varphi, \Theta)$ which has been calculated from the ratio of meridional PV flux by transient eddies and the meridional gradient of density weighted PV [Eq. (11)]. In Fig. 2 the meridional gradient of density weighted PV [denominator in Eq. (11)] is plotted

together with the zonally averaged tropopause (thick dashed line). For comparison with other studies, e.g. Yang et al. (1990), our shown gradient is multiplied by $\cos \varphi$. The position of the subtropical jet maximum is marked by capital " $J$ ". Generally, it can be seen that the gradient is positive everywhere. The dominant feature in both hemispheres and in all seasons is the gradient maximum along the tropopause. Local maxima always appear near the jet position. A further maximum occurs in the SH polar lower stratosphere in July and October. It marks the edge of the polar vortex. In October at $60^{\circ} \mathrm{S}$ it is extended far downwards and a second, high-latitude maximum at the tropopause is to be seen.

In Fig. 3 the corresponding PV flux by transient eddies, multiplied by $\cos \varphi$ [the numerator in Eq. (11)] shows a maximum of southward (negative) flux near the tropopause in all seasons. Similar to the gradient pattern in Fig. 2 it is restricted to a band of $\pm 20 \mathrm{~K}$ along the tropopause (thick solid line) in both hemispheres. Note that this is approximately equivalent to $200-250 \mathrm{hPa}$. In this region there is no remarkable difference between the maximum values of both hemispheres in January, April and October, whereas in July, SH flux is significantly stronger. In $\mathrm{SH}$ winter the downgradient flux maximum is nearly twice as strong as in $\mathrm{NH}$ winter. 

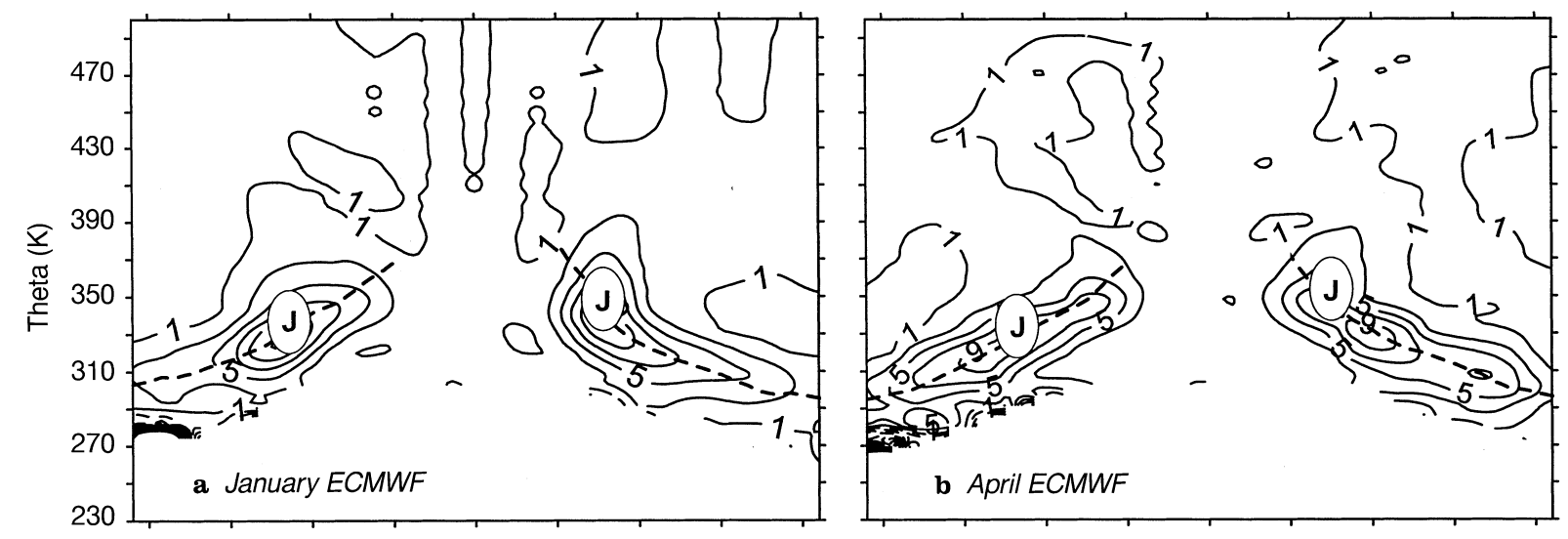

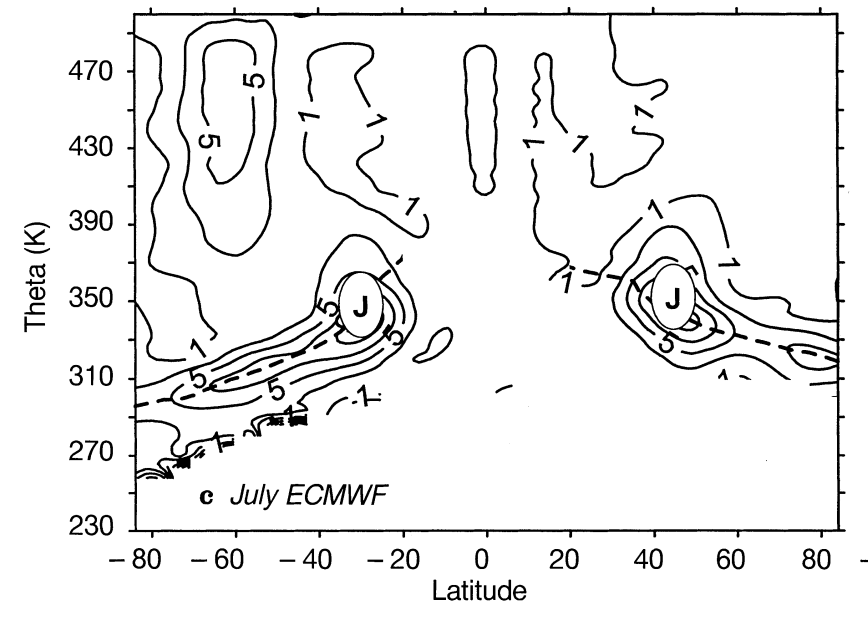

Fig. 2a-d. Meridional gradient of the density weighted zonally averaged PV multiplied by $\bar{\rho}_{\Theta} \cos \varphi$ in $10^{11} \mathrm{~m}^{-1} \mathrm{~s}^{-1}$ from ECMWF analysis for 4 months. Meridional derivative is defined with respect to

Seasonal variation of the maximum flux is weaker in the $\mathrm{NH}$. In the SH the winter maximum is approximately twice as strong as that in summer. In both hemispheres the latitudinal position of the maximum varies between $45^{\circ}$ and $55^{\circ}$. The vertical position moves from 310 to $340 \mathrm{~K}$ from winter to summer in the $\mathrm{SH}$ and from 300 to $340 \mathrm{~K}$ in the NH. The location of the maximum negative flux is exactly at the dynamically defined zonally averaged tropopause in SH summer and NH autumn and slightly shifted above the tropopause in NH summer and below the tropopause in spring and SH autumn. It is clearly below the tropopause in winter of both hemispheres.

Small regions with weak northward (positive) PV flux occur above the zonally averaged tropopause at $\left\{40^{\circ}-50^{\circ} \mathrm{N} ; 350-355 \mathrm{~K}\right\} 10^{\circ}-20^{\circ}$ polewards of the subtropical jet in January and April and at $\left\{40^{\circ}-60^{\circ} \mathrm{S} ; 340 \mathrm{~K}\right\}$ also $10^{\circ}-20^{\circ}$ polewards of the subtropical jet in July. Further positive regions can be found in the northern hemisphere at $\left\{55^{\circ} \mathrm{N}, 330 \mathrm{~K}\right\}$ in January as well as around $\left\{35^{\circ} \mathrm{N} ; 330 \mathrm{~K}\right\}$ in July and October and at $\left\{22^{\circ} \mathrm{N}, 365 \mathrm{~K}\right\}$ in July. A test for statistical significance of the sign in these positive flux regions failed except for the last one in NH tropics in July. This is due to the strong interannual fluctuation in these regions.

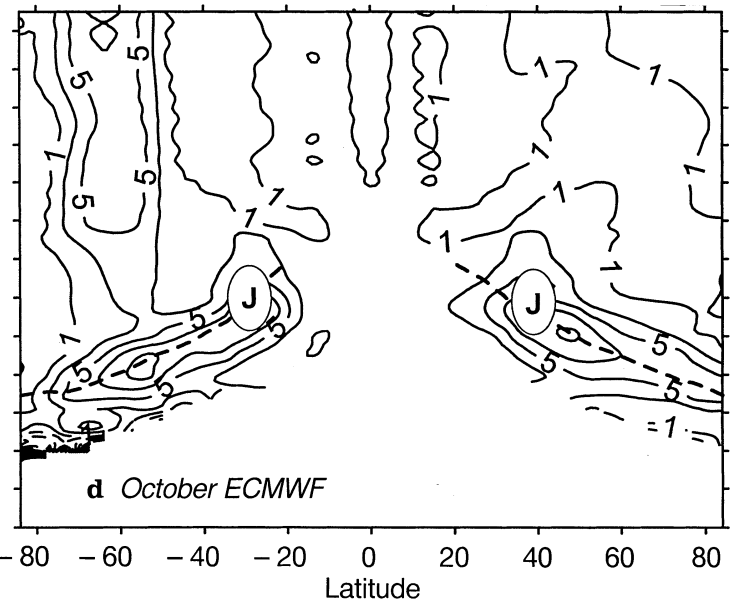

$y=a \cdot \sin \varphi$. The contour interval is 2 . Thick dashed lines mark the dynamical tropopause. Capital "J" marks the subtropical jet positions

In the lower stratosphere meridional PV fluxes by transient eddies are much weaker than in the vicinity of the tropopause. In the $\mathrm{SH}$ they are concentrated between $20^{\circ} \mathrm{S}$ and $40^{\circ} \mathrm{S}$ and in the $\mathrm{NH}$ between $40^{\circ} \mathrm{N}$ and $60^{\circ} \mathrm{N}$. In the $\mathrm{NH}$ winter flux regions with alternating sign reach from the mid-latitude tropopause to the upper boundary of our data set in the polar lower stratosphere.

With the climatological gradients and fluxes illustrated, Eq. (11) gives an $K_{y y}(\varphi, \Theta)$ shown in Fig. 4. For comparison with other studies, our $K_{y y}$ is multiplied by $\cos ^{2} \varphi$. Shaded areas mark height-latitude regions where statistical error is lower than $100 \%$ and therefore the sign of $K_{y y}$ is significant.

It is apparent that the maxima of flux along the tropopause are compensated to a large degree by the gradient maxima, so that no enhanced $K_{y y}$ is observed there. Regions with large mixing coefficients $\left(>4 \cdot 10^{5} \mathrm{~m}^{2} \mathrm{~s}^{-1}\right)$ are found in mid-latitudes in the middle troposphere at about $300 \mathrm{~K}$ except in summer, when, as already shown, the PV flux maximum is at or slightly above the tropopause. $K_{y y} \cos ^{2} \varphi$ the middle troposphere has its largest value of $10 \cdot 10^{5} \mathrm{~m}^{2} \mathrm{~s}^{-1}$ in SH winter and of $7 \cdot 10^{5} \mathrm{~m}^{2} \mathrm{~s}^{-1}$ in NH winter.

In the winter and spring of both hemispheres and in $\mathrm{SH}$ April an additional region of more efficient mixing 



Fig. 3a-d. Zonally averaged meridional transient eddy PV flux multiplied by $\cos \varphi$ in $10^{-5} \mathrm{~m} \mathrm{~s}^{-2}$ from ECMWF analysis for 4 months. The contour interval is 0.5 . Negative contours are dashed.

Regions below 0.25 are shaded. Thick solid lines mark the dynamical tropopause. Capital "J" marks the subtropical jet positions

can be seen from the subtropical troposphere to the upper boundary of the considered region. This subtropical pattern is correlated to a band of weak zonal wind marked by thick dashed lines.

In the NH in all seasons one finds significant mixing regions outside the subtropics in the mid-latitude lower stratosphere between 370 and $470 \mathrm{~K}$. They cover the whole extratropical stratosphere up to $70^{\circ} \mathrm{N}$ and are strongest in April and October. Maximum values of $K_{y y}$ are at $4-12 \cdot 10^{5} \mathrm{~m}^{2} \mathrm{~s}^{-1}$.

Regions of negative $K_{y y}$ mark climatological upgradient PV flux. A significant negative region in midlatitudes occurs only at $40^{\circ} \mathrm{N}$ in April polewards of the subtropic jet. The striking but statistically insignificant negative $K_{y y}$ layer in the NH lower stratosphere in July is the result of a very small and negative gradient not resolved in Fig. 2c. It has to be stressed that these extreme values, as well as those in the NH January stratosphere and the blobs near the south pole in April and October are statistically insignificant.

\subsection{Mean meridional circulation from ECHAM3 data}

Because the mean meridional stream function in the ECHAM3-T21 runs strongly deviates from ECMWF

results in the lower stratosphere, we have also calculated a mean circulation based only on heating rates. The meridional mass flow rate, $\bar{V}_{d}$, directly derived from meridional wind, $v$, and isentropic mass density [Eq. (4)] and $\bar{V}_{\text {con }}$, calculated by Eqs. $(4),(6 \mathrm{a}, \mathrm{b})$ from $Q$ via $\bar{W}$ and $\Psi_{Q}=\Psi_{v}$ as described in Sect. 2 are shown in Fig. $5 \mathrm{a}, \mathrm{b}$ for April. Except for smaller quantitative differences in the middle troposphere, there is good agreement of the maxima in the subtropical upper troposphere at $350 \mathrm{~K}$. The most striking difference is the stronger meridional mass flow rate, $\bar{V}_{d}$, in the subtropical lower stratosphere between $390 \mathrm{~K}$ and the upper boundary. If one takes $\bar{V}_{d}$ from the ECMWF analysis (Fig. 5c) as reference, it turns out that the model has an unrealistic circulation in the lower stratosphere. The results for other months (not shown) are similar.

Despite this shortcoming of the model it is possible to derive a realistic mean meridional mass circulation, $\Psi_{Q}$, from the diabatic heating rate terms occurring in the temperature tendency equation of ECHAM3 (GCCC, 1993). This is shown in Fig. 6a for January and in Fig. 6b for July. As in the analysis data this mean meridional circulation is strongest in winter and of similar strength in both hemispheres in spring and autumn (not shown). In summer and spring we find small cells with opposite sign at $310 \mathrm{~K}$ between $30^{\circ}$ and $40^{\circ}$ not occurring in the 

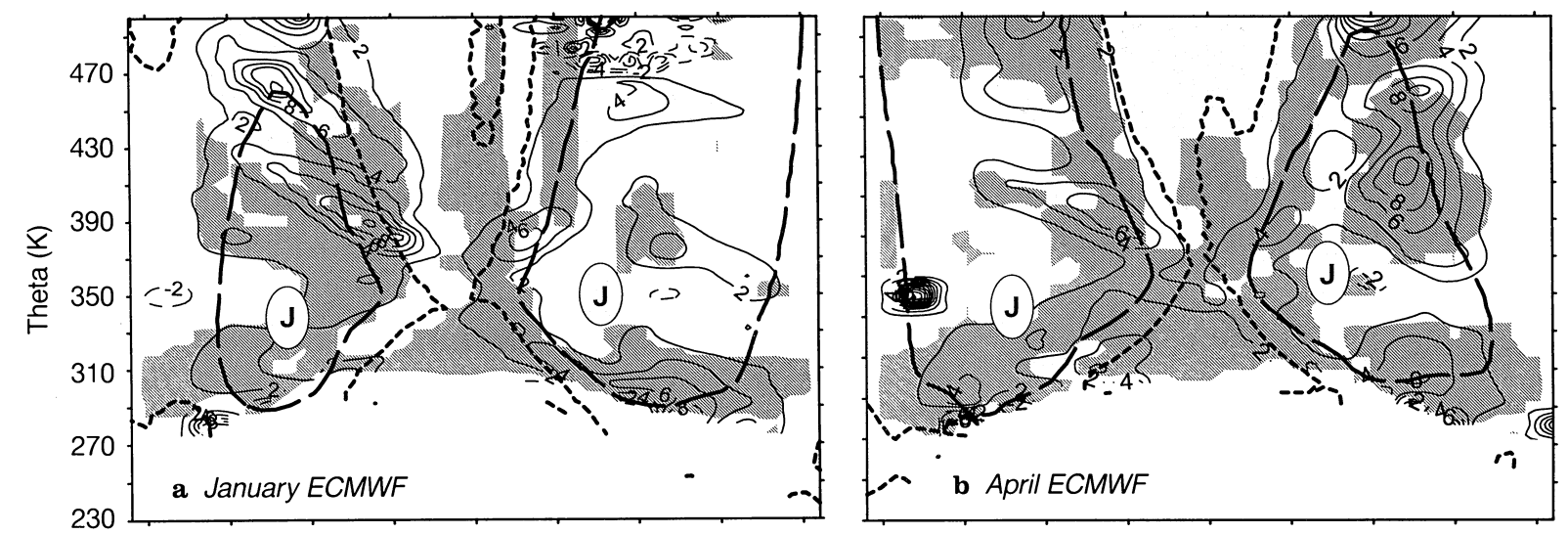

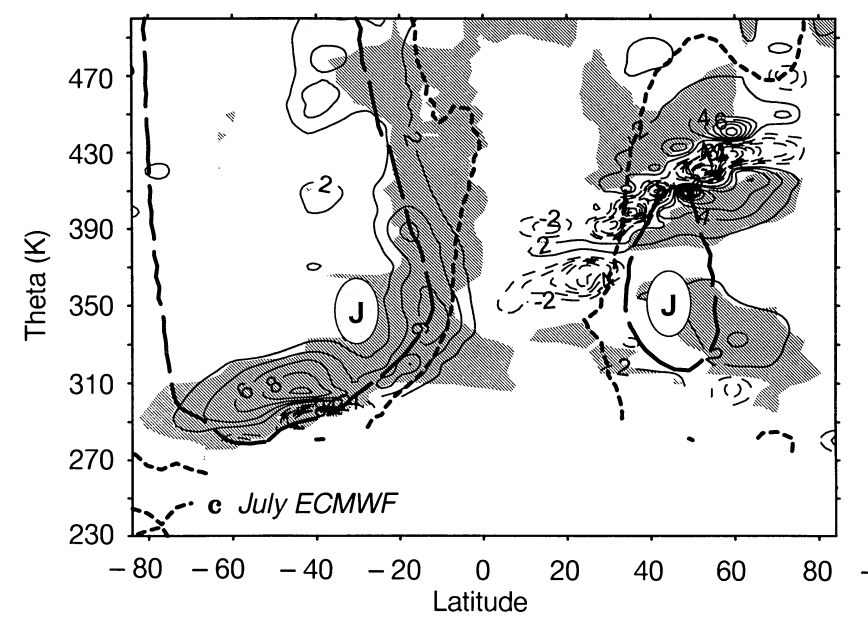

Fig. 4a-d. Isentropic eddy mixing coefficient $K_{y y} \cos ^{2} \varphi$ in $10^{-5} \mathrm{~m}^{2} \mathrm{~s}^{-1}$ from ECMWF analysis for 4 months. In the shaded area sign is statistically significant with a probability of $95 \%$. Negative contours are marked by thin dashed lines. The contour interval is 2 .

circulation calculated from the analysis data (Fig. 1). They are superimposed onto a tropospheric circulation which is otherwise very similar to the analysis result in shape and strength. In winter and autumn mean meridional circulation in the Hadley branch is more intense in the model by 4 to $8 \cdot 10^{10} \mathrm{~kg} \mathrm{~s}^{-1}$. Because no artificial upper boundary condition is necessary for Eq. (6b), $\Psi_{Q}$ reaches higher into the stratosphere than $\Psi_{v}$ from analysis data (Fig. 1). Despite an extension of the considered height range compared to the analysis result, it comes out again that in mid-latitudes strong mass circulation is confined to the region below the zonally averaged tropopause (thick solid line). In analogy to the analysis result, the NH summer tropopause (Fig. 6b) is up to $20 \mathrm{~K}$ higher than the tropopause in SH summer (Fig. 6a).

\subsection{Eddy flux parameterization based on ECHAM3}

Analogous to Sect. 4.2, the first model result presented is the meridional PV gradient (Fig. 7) and the meridional PV flux by transient eddies (Fig. 8), both given only for January (part a) and July (part b). Figure 7 shows that the gradient is positive almost everywhere again. Deviations from the analysis result occur in the $\mathrm{SH}$.

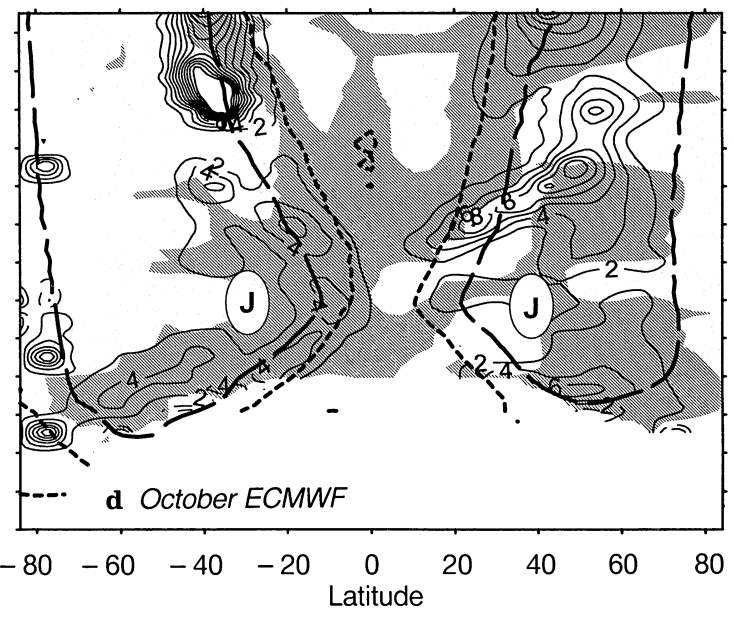

Zonally averaged wind-speed contours are thick and short dashed $\left(0 \mathrm{~m} \mathrm{~s}^{-1}\right)$ and thick and long dashed $\left(10 \mathrm{~m} \mathrm{~s}^{-1}\right)$. Capital "J" marks the subtropical jet positions

Generally, the ECHAM3 PV gradient is larger and the tropopause maximum is more extended to the lower stratosphere. Additional tropopause maxima occur at $60^{\circ} \mathrm{S}$ in January (Fig. 7a) and April (not shown). The negative region in the polar winter stratosphere does not occur in the gradient calculated from the analysis data.

In Fig. 8 the meridional transient eddy PV flux of ECHAM3 is shown for January (a) and July (b). As in the ECMWF-analysis result (Fig. 3), we find the strongest negative flux in the vicinity of the zonally averaged tropopause (thick solid line). Negative flux regions are always weaker than in the analysis. Their shape is less homogeneous and the position of their maxima clearly differs from the analysis results except in NH July and NH October. The strongest deviations are found in NH January, where no maximum appears below the tropopause, and in SH January, where the maximum is split up into a maximum shifted by $10^{\circ}$ polewards and by $10 \mathrm{~K}$ downwards compared with the maximum in the analysis data and into a maximum above the tropopause at $40^{\circ} \mathrm{S}$. In agreement with the analysis data result, the maximum position is slightly above the tropopause in NH summer and below it in both hemispheres in spring and $\mathrm{SH}$ winter. In the other 

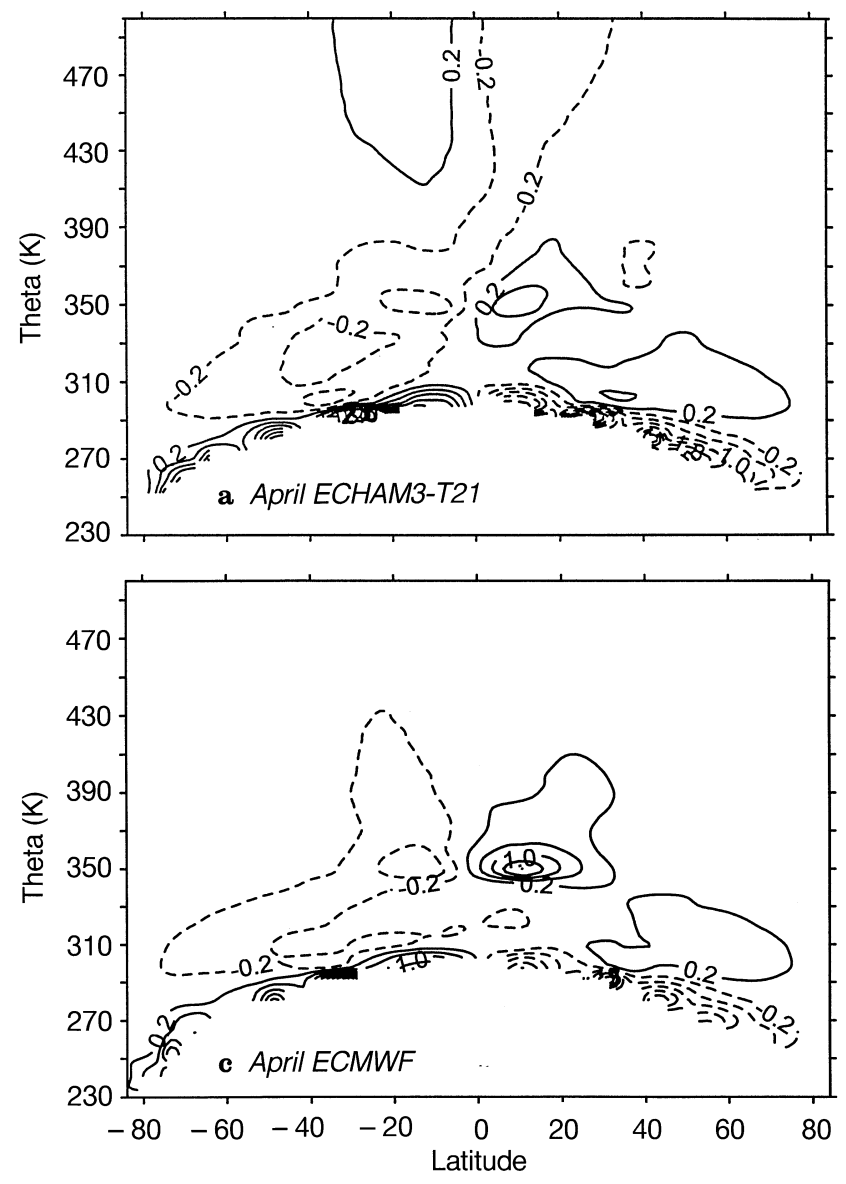

four cases there is no agreement in the relative position of tropopause and negative flux maximum.

In all seasons in both hemispheres, we find a significant northward flux of PV above the zonally averaged tropopause poleward of the subtropical jet. Small northward flux regions located in the troposphere at $\sim 50^{\circ} \mathrm{N}$ in July and at $50^{\circ} \mathrm{S}$ in January do also appear in the flux from the analysis data. As expected from geostrophic balance condition (Tung, 1986), the position

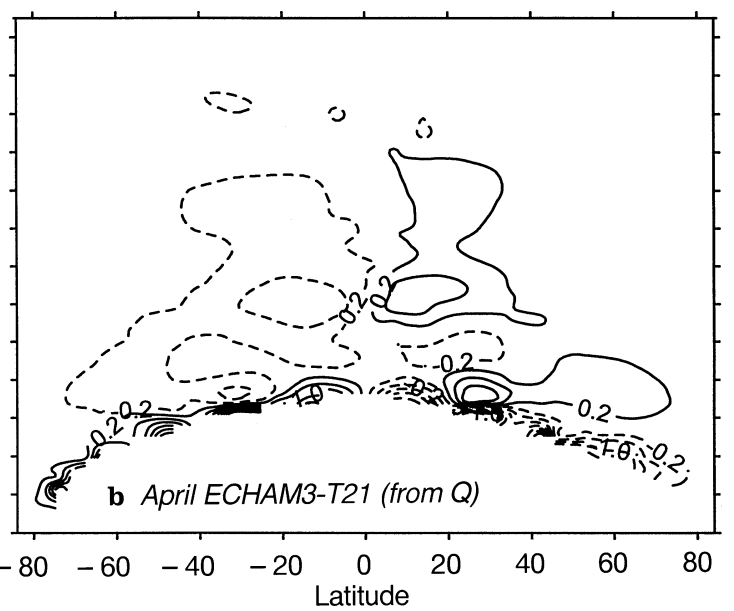

Fig. 5a-c. Isentropic mean meridional mass flow rate $\bar{V}_{d} / \bar{\rho}_{\Theta}$ or $\bar{V}_{\text {con }} / \bar{\rho}_{\Theta}$, respectively, in $\mathrm{m} \mathrm{s}^{-1}$ for April from a ECHAM3-T42 $\left(\bar{V}_{d}\right)$, b ECHAM3-T21 ( $\left.\bar{V}_{\text {con }}\right)$ and c from ECMWF analysis $\left(\bar{V}_{d}\right)$. The contour interval is 0.4 and negative contours are dashed

of these summer phenomena is slightly above the small circulation cells found in $\Psi_{Q}$ (Fig. 6).

In Fig. 9 we present $K_{y y} \cos ^{2} \varphi$ based on the ECHAM3T42 experiment. Like the ECMWF-analysis-based result (Fig. 4), the dominant feature is the combination of regions of more efficient mixing with the subtropical band of weak zonally averaged zonal wind (thick dashed lines). Typical values in significant regions (shaded) are again between 2 and $8 \cdot 10^{5} \mathrm{~m}^{2} \mathrm{~s}^{-1}$ but the maxima in the
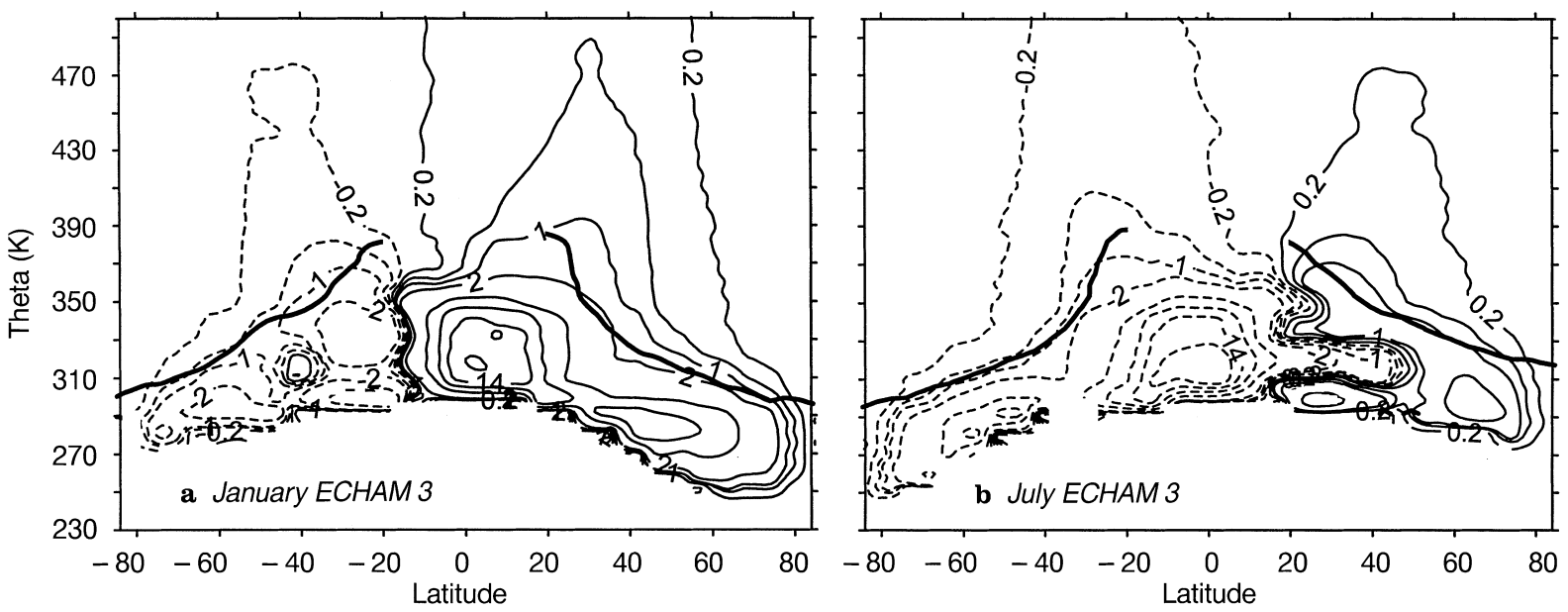

Fig. 6a, b. Isentropic mass streamfunction, $\Psi_{Q}$ in $10^{10} \mathrm{~kg} \mathrm{~s}^{-1}$ from ECHAM3-T21 experiments for a January and b July. Contour parameters are the same as in Fig. 1 

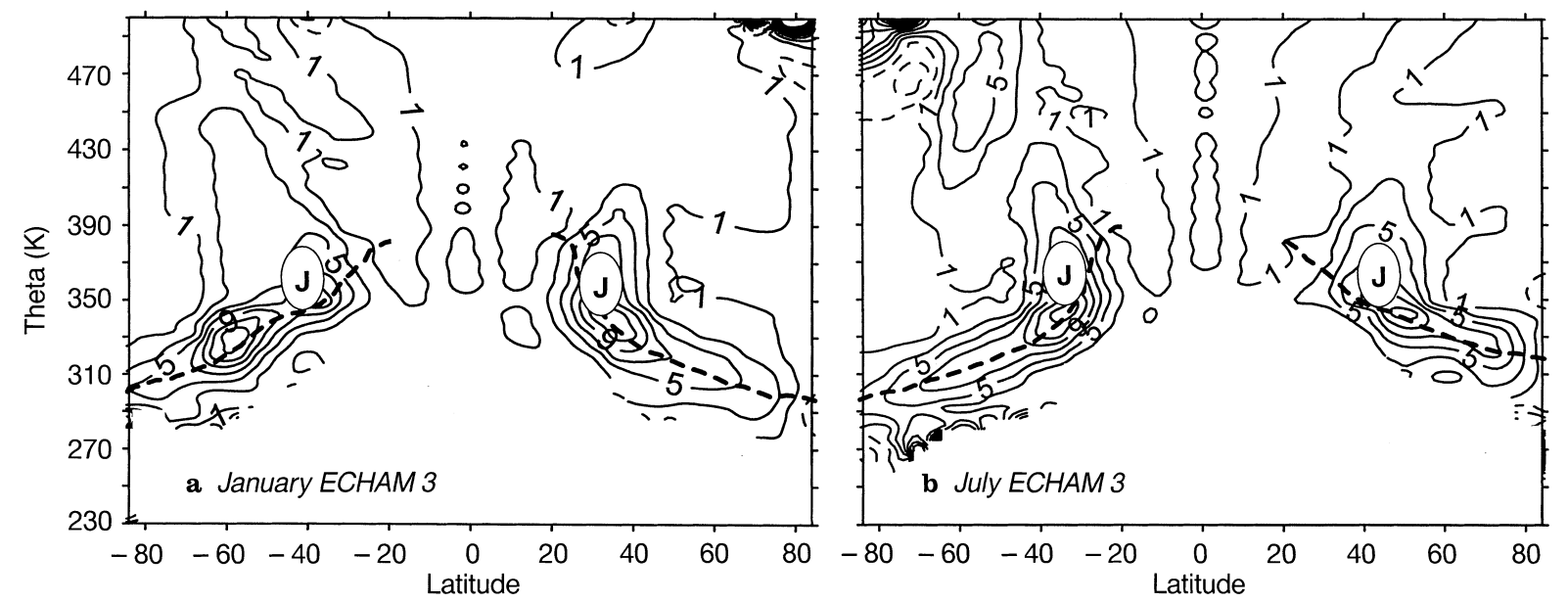

Fig. 7a, b. Same as in Fig. 2 for a January and b July but from ECHAM3 experiments. Negative contours are dashed
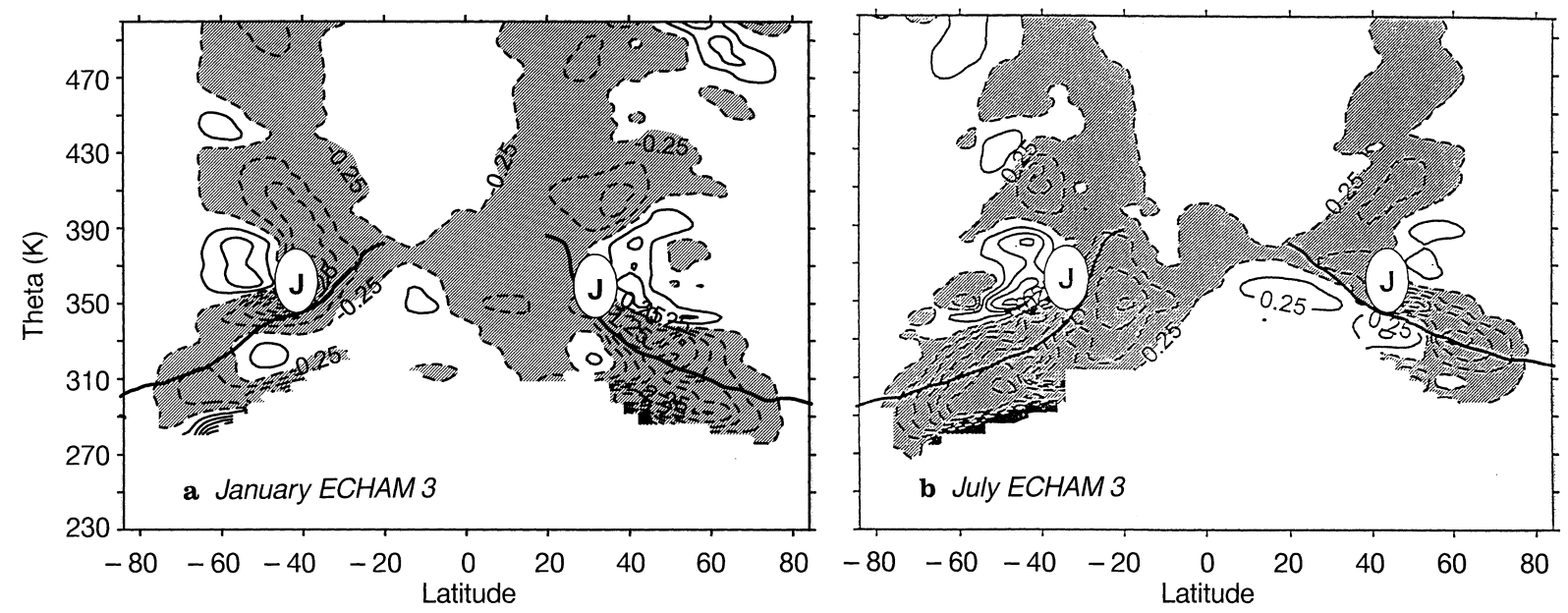

Fig. 8a, b. Same as in Fig. 3 for a January and b July but from ECHAM3 experiments
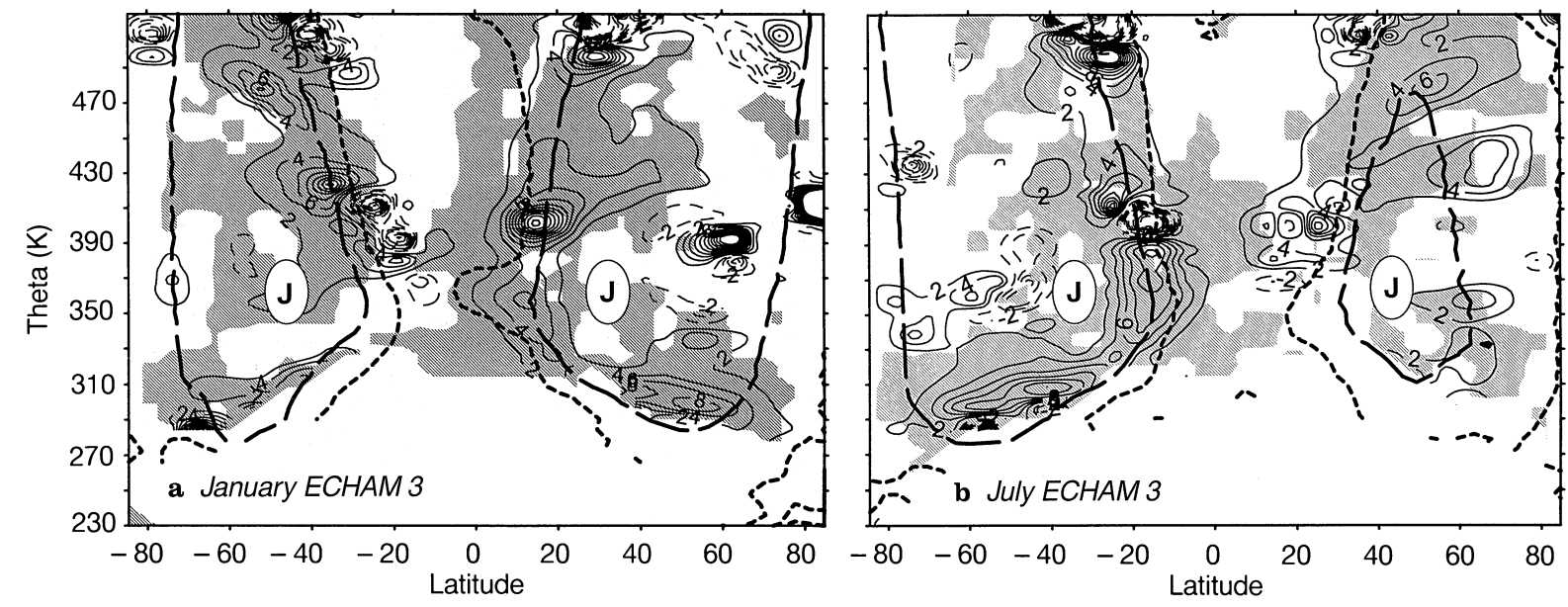

Fig. 9a, b. Same as in Fig. 4 for a January and b July but from ECHAM3 experiments

subtropical troposphere are stronger and more localized than those of the analysis-based $K_{y y}(\varphi, \Theta)$.

Generally, the area of significant $K_{y y}$ sign is enlarged compared with the analysis data result. From the statistical point of view the characteristic $K_{y y}$ pattern discussed in Sect. 4.2. is now better founded. As already discussed, the striking blobs mark a limitation of the method; again, they are statistically insignificant. 
Further qualitative agreement can be pointed out in the lower stratosphere. Again in the $\mathrm{NH}$, the region of significant mixing is extended to middle and polar latitudes. The phenomenon of significant $K_{y y}$ values inside the region of easterly winds in the SH January stratosphere is also to be seen, though somewhat weaker, in ECHAM3 in the same height range.

Middle- and upper-tropospheric mixing regions from analysis and from ECHAM3 have similar shape and strength except in SH January. The strongest significant mixing is again found at $300-310 \mathrm{~K}$ in the winter hemispheres with values up to $8 \cdot 10^{5} \mathrm{~m}^{2} \mathrm{~s}^{-1}$ (January) and $14 \cdot 10^{5} \mathrm{~m}^{2} \mathrm{~s}^{-1}$ (July).

Negative $K_{y y}$ values polewards of the subtropical jet in both hemispheres and in all months reflect the positive PV flux observed at this position. They are stronger in winter than in summer. In the analysis data similar negative regions are observed only in $\mathrm{NH}$ winter and spring.

\section{Discussion}

The estimation of the distribution of minor constituents demands a consistent calculation of mean meridional circulation and wave-induced mixing. The ECMWFanalysis and ECHAM3-model data are used in order to create such a data set. The basic assumption is that adiabatic processes dominate in the upper troposphere und lower stratosphere at mid-latitudes. This is taken into account in Eqs. (9) and (11), the equations used for calculating mixing coefficients. The PV gradient, see Figs. 2 and 7, is continuously positive in the considered height region for ECMWF analysis as well as for ECHAM3-model data. The PV flux (Figs. 3 and 8) has mainly negative values. This is in agreement with lifecycle experiments, e.g. Thorncroft et al. (1993), hereafter THM. But the adiabatic approximation is not necessary to calculate the PV flux in the case where observational or model data are directly used. Furthermore, the divergence of Eliassen-Palm flux on isentropes was estimated with the mean momentum budget equation and compared with results of PV flux. This calculation was carried out for ECHAM3-T21-model data. It shows between both quantities a good agreement. This supports the idea that the adiabatic approach is valid above the boundary layer. Only in the tropics does the diabatic term have a large influence on PV flux. In the extratropics the diabatic expression has only a small effect in the calculation of the mixing coefficients in the above mentioned height region. Note that Tung (1986) used a corresponding approach in the stratosphere.

Generally, our $K_{y y}$ result neither shows enhanced meridional mixing efficiency at the dynamic zonally averaged tropopause, nor a special horizontal mixing barrier at this zonal mean PV contour. However, in the vicinity of the subtropic jet in winter and spring, $K_{y y}$ is reduced noticeably (Fig. 4), an indication for reducing of mixing in that region of the troposphere. Such a latitudinal dependence was also found by Pierrehumbert and Yang (1993) by means of isentropic trajectory

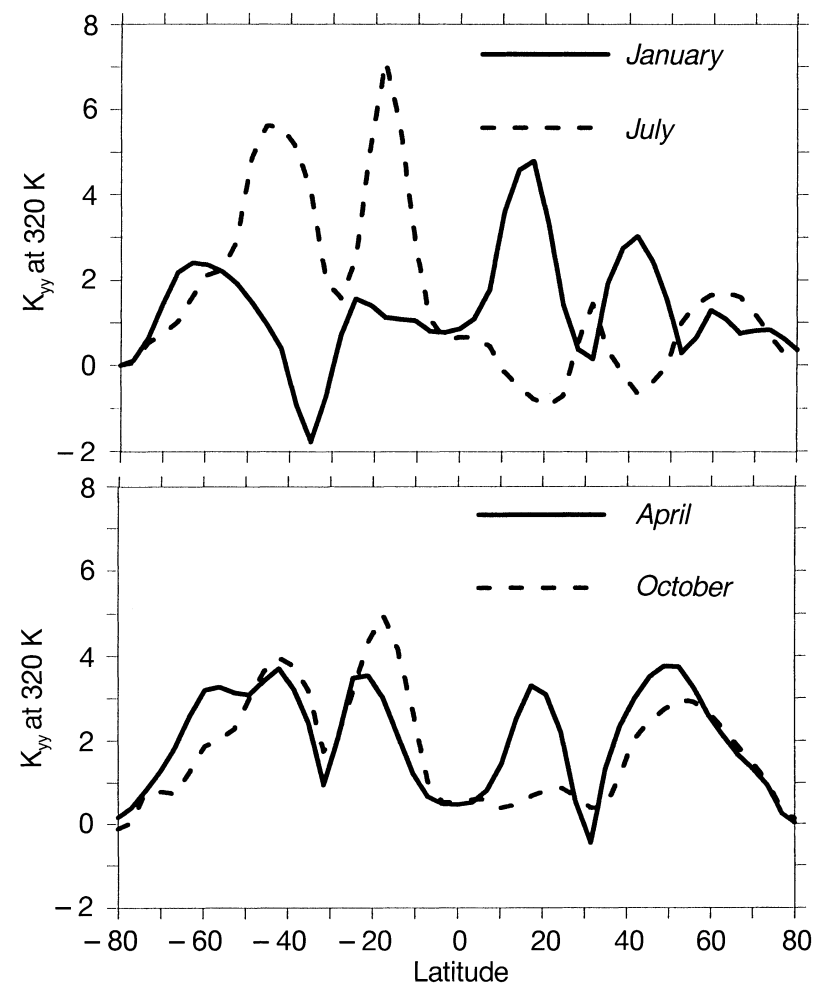

Fig. 10. Isentropic eddy mixing coefficient $K_{y y} \cos ^{2} \varphi$ in $10^{5} \mathrm{~m}^{2} \mathrm{~s}^{-1}$ at $320 \mathrm{~K}$ from ECMWF analysis for all seasons

calculations with GCM winds and by Chen (1995) using a semi-Lagrangian transport model and ECMWF-analysis winds. In Fig. 10 the annual cycle of $K_{y y}$ at a height of $320 \mathrm{~K}$ shows a mixing barrier at $30^{\circ}-35^{\circ}$ (marked by a local minimum) in all seasons, except in NH July. In spring, autumn and winter it separates two distinct mixing regions around $15^{\circ}-20^{\circ}$ and around $40^{\circ}-50^{\circ}$. In NH summer the whole barrier pattern appears shifted northwards by approximately $20^{\circ}$. In $\mathrm{SH}$ summer the mid-latitude mixing region reaches up to $70^{\circ} \mathrm{S}$. The barrier is stronger in the $\mathrm{NH}$, whereas mixing is more efficient in SH winter and spring. Comparison with Fig. 4 yields that the mixing region at lower latitudes seems to be the tropospheric extension of the stratospheric "surf zone" where Rossby-wave breaking is the dominant mixing mechanism, as will be discussed. For a discussion of effects of asymmetric flow on Rossby-wave breaking we refer to Nakamura and Plumb (1994).

The fact that the tropospheric subtropical zone of more efficient mixing reaches up continuously to the stratospheric breaking zone in both hemispheres, except in summer, supports the argumentation of THM and Chen (1995) that a similar Rossby-wave breaking mechanism can be found slightly polewards of a critical line at the equatorward edges of the polar vortex (McIntyre and Palmer, 1983, 1984) and of the subtropical tropopause jet. This critical line is defined by $(u-c)=0$, where $c$ is the phase velocity of the baroclinic wave. For stratospheric conditions a theoretical description and quantification of this relation between wave breaking and enhanced $K_{y y}$ values has 


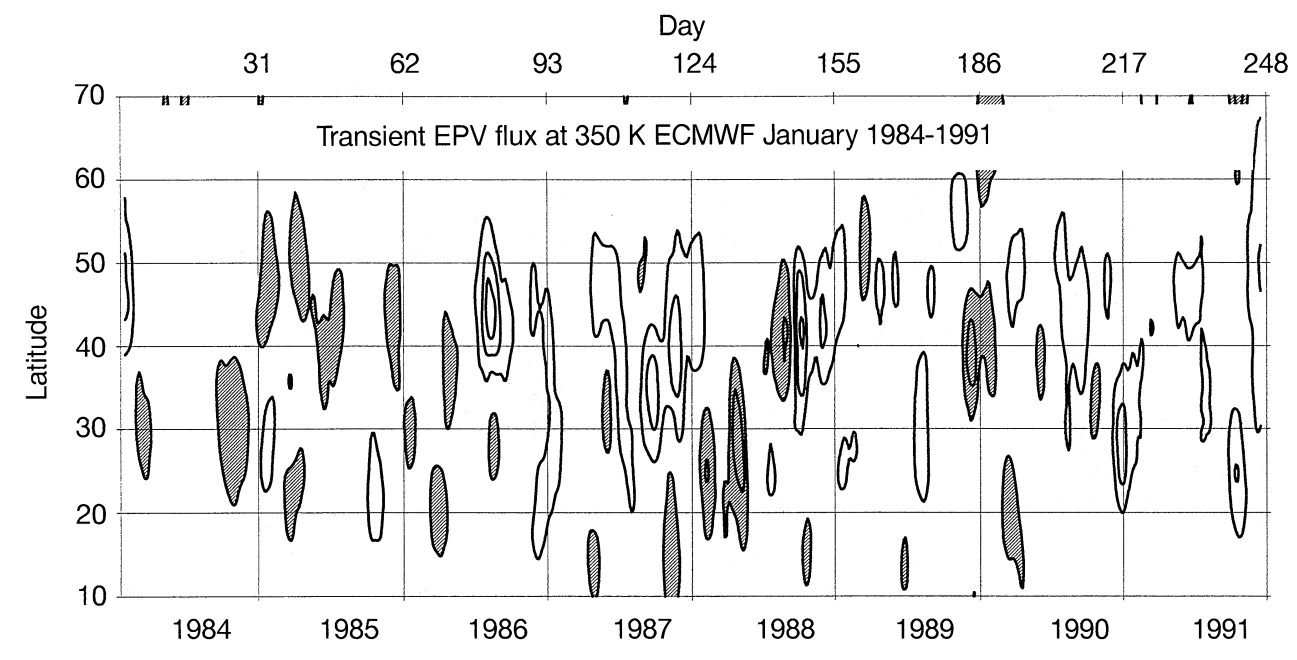

Fig. 11. Time-series of northernhemisphere January zonally averaged meridional transient eddy PV flux in $10^{-5} \mathrm{~m} \mathrm{~s}^{-1}$ at $350 \mathrm{~K}$ from ECMWF analysis 1984-1991. Daily fluxes were smoothed out by 7-day running averaging. Regions with values below 2 are shaded; the contour interval is 2; zero contour is left out; vertical grid lines mark the interruptions at 31 January of each year been derived by Garcia (1991) and verified with 12 years' analysis data by Randel and Garcia (1994).

A feature of the isentropic diagnostic of the analysis data hard to understand by life-cycle experiments is the positive flux region polewards of the subtropical jet in a region of positive PV gradient (Figs. 2 and 3). With Eq. (9) it leads to an unphysically negative $K_{y y}$ coefficient. A positive Eliassen-Palm flux divergence in that region is also found in pressure coordinate diagnostics of climatological data (Edmon et al., 1980; Karoly, 1982; Schmitz and Dethloff, 1984; James, 1994). We have already mentioned that diabatic effects should not be responsible for that. Also, Fig. 2, for instance, shows no reduced and no negative PV gradients there, and it seems that frictional processes are not dominant. For the ECHAM3-model data (Fig. 8), the positive PV flux values are stronger than for the analysis one. Generally, the PV flux structure of the model and analysis are similar, but with an extreme positive value in lower latitudes in July, see for instance Figs. 8b and 3c. Karoly (1982) lists possible causes of the upgradient flux. These are non-linearity in the decay phase of the baroclinic life cycle, diabatic effects associated with deep moisture convection, neglected ageostrophic effects and a local gradient differing from the zonal mean in the region of eddy activity. Indeed, very weak positive PV flux is already inherent in idealized anticyclonic shear-type lifecycle experiments in the height-latitude region where EP flux direction turns from upwards to equatorwards in the upper-tropospheric saturation stage. We have carried out adiabatic life-cycle experiments with a simplified version of the ECHAM3-GCM and obtain a similar positive flux region. Because the isentropic formulation applied here is non-geostrophic, neither diabatic effects nor neglected ageostrophic terms explain the phenomenon. These experiments suggest that upgradient flux is at least partly caused by non-linearity. Nevertheless, the question remains as to why this positive flux in the ECMWF analysis is much stronger than in the idealized life-cycle experiments already mentioned. We consider transient eddy PV flux at the height of the positive flux maximum $(350 \mathrm{~K})$ in its time and longitude dependence. In Fig. 11 a January time-series of flux filtered by a 7-day running mean illustrates the strong interannual variability at this height. From Fig. 11 it becomes obvious that climatological net positive flux between $40^{\circ}$ and $50^{\circ}$ latitude appearing in Fig. 3a mainly results from the large contributions in the years 1986-1988. On the other hand, we find strong negative flux in January 1985. Comparison of NH height-latitude structure of PV flux for both years with strongest negative and positive flux at $350 \mathrm{~K}$ between $40^{\circ}$ and $50^{\circ} \mathrm{N}$ (1985, 1986, Fig. 12) yields that negative and positive flux regions between 290 and $350 \mathrm{~K}$ were weaker in 1985 . Positive flux between $30^{\circ} \mathrm{N}$ and $45^{\circ} \mathrm{N}$ at $350 \mathrm{~K}$ completely disappears in 1985 , whereas the $50^{\circ} \mathrm{N}$ flux maximum at 330-340 K remains. In Fig. 13 the monthly mean of the zonal wind speed at $350 \mathrm{~K}$ from both Januaries is compared, and we find a much stronger Atlantic jet in 1985 which is zonally orientated in contrast to the Atlantic jet in 1986 which has an SW-NE orientation. The Pacific jet streams in both years are similar and zonally oriented.

The existence of favoured longitude regions for the amplification of baroclinic disturbances and the temporal alternating flux directions in the successive evolution stages of the baroclinic waves result in a horizontal flux pattern reflecting the stationary wave structure in the NH (Lau, 1979). The distribution of climatological PV flux at the $350-\mathrm{K}$ surface is shown in Fig. 14a and its zonal average in Fig. 14b. In contrast to the $\mathrm{SH}$ (not shown), in the $\mathrm{NH}$ a remarkable longitudinal dependence occurs. In detail, disturbances causing negative PV flux reach the $350-\mathrm{K}$ level in the entrance region of the jet between $20^{\circ} \mathrm{N}$ and $40^{\circ} \mathrm{N}$ over the east of North America and over the eastern part of Asia. East of these regions positive flux regions follow which are shifted northwards in respect to the negative flux maxima. Strong regional flux nearly cancel in the zonal average between $10^{\circ}$ and $40^{\circ} \mathrm{N}$ (Fig. 14b). Northward shift during the propagation stage of the baroclinic disturbances in the NH causes a more incomplete flux cancellation in the zonal average than in the idealized model experiments without longitudinal dependence. This leads to enhanced positive mean flux between $40^{\circ}$ and $50^{\circ} \mathrm{N}$. The northeastward shift may be caused by a 

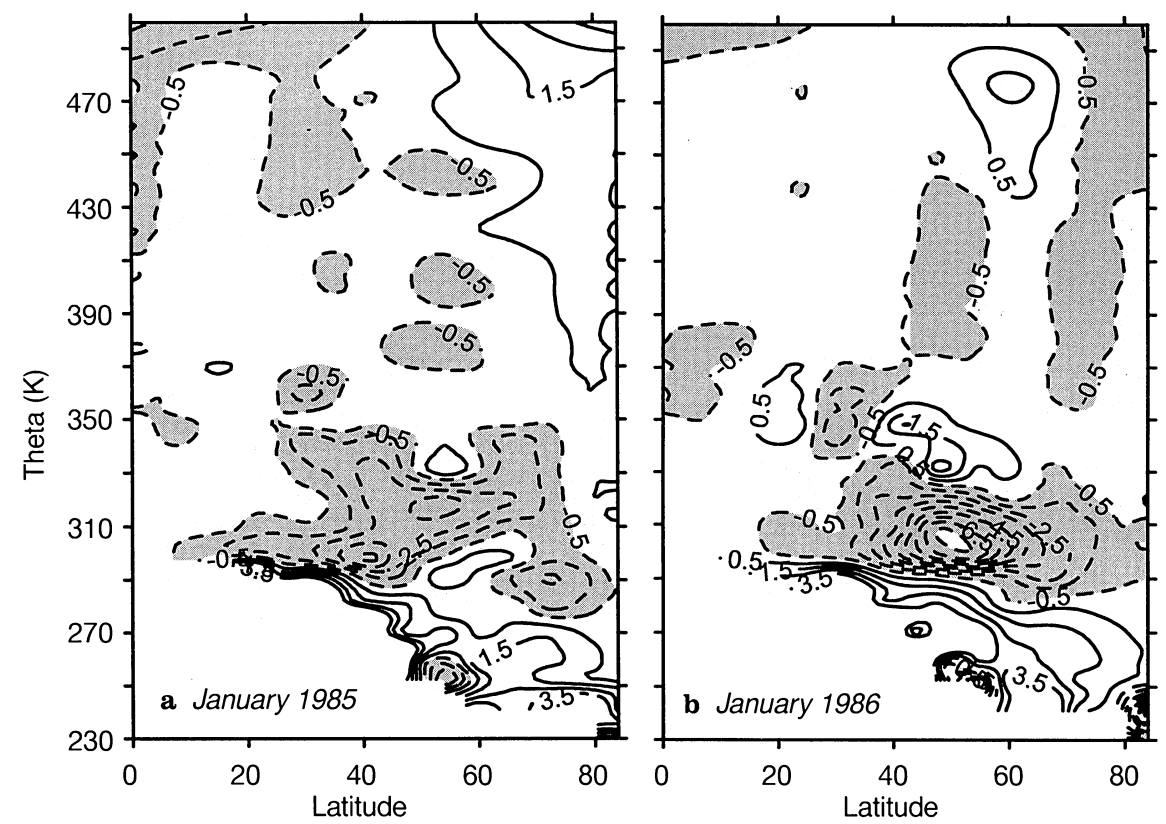

Fig. 12a, b. Zonally averaged meridional transient eddy PV flux in $10^{-5} \mathrm{~m} \mathrm{~s}^{-2}$ from ECMWF analysis for northern-hemisphere January in a 1985 and b 1986. The contour interval is 1 ; negative contours are dashed southwest-northeast orientation of the mean Atlantic jet as suggested by the different orientation of the jet axis in the years of extreme positive and negative PV flux at $350 \mathrm{~K}$ (Fig. 13).

Further confirmation of the suggested latitudinal shift of baroclinic wave fluxes can be found in Randel (1990), where 6 years of ECMWF-analysis data have been statistically analysed. Based on TEM formalism, it is shown (in his Fig. 10 c) that the successive maxima of Eliassen-Palm flux divergence with opposite sign at $300 \mathrm{hPa}$ are shifted by about $4^{\circ}$ in the $\mathrm{NH}$.

In the $\mathrm{SH}$ both maxima positions are exactly at the same latitude. So arguments of the $\mathrm{NH}$ can not be applied here. It could be that positive values of PV flux and negative $K_{y y}$ already appearing in idealized life-cycle experiments are due to non-linear processes. a January 1985

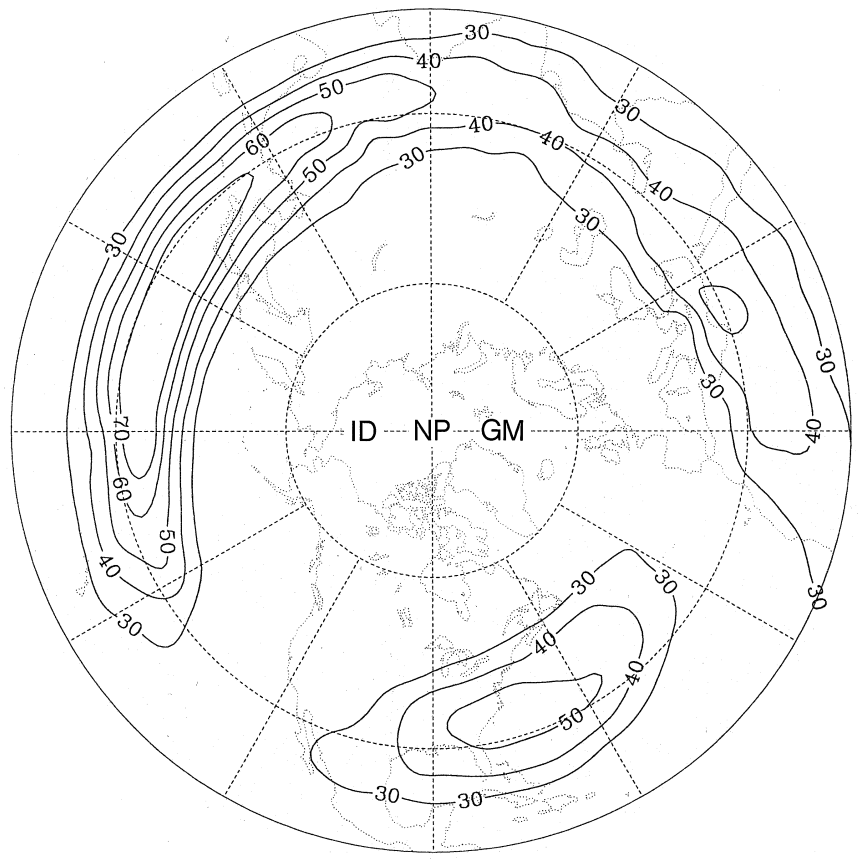

Contour from $30 \mathrm{~ms}^{-1}$ to $70 \mathrm{~ms}^{-1}$ b January 1986

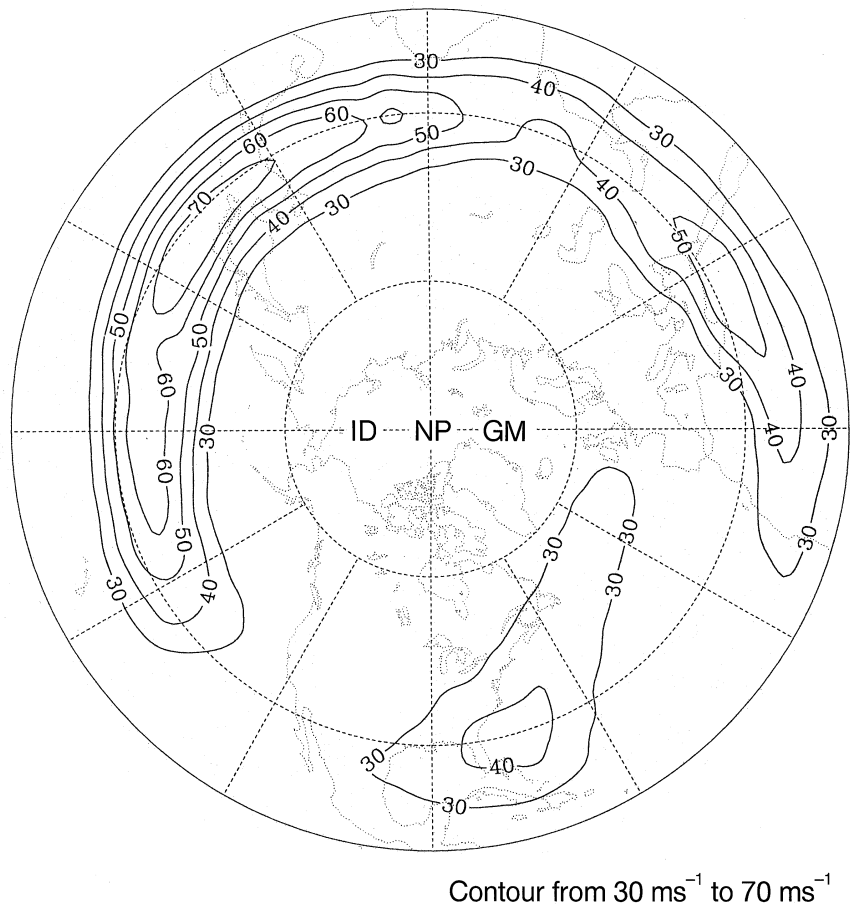

Fig. 13a, b. Monthly mean zonal wind in $\mathrm{m} \mathrm{s}^{-1}$ at the $350-\mathrm{K}$ surface in northern hemisphere January a 1985 and b 1986 . Only contours $\geq 30 \mathrm{~m} \mathrm{~s}^{-1}$ are drawn 


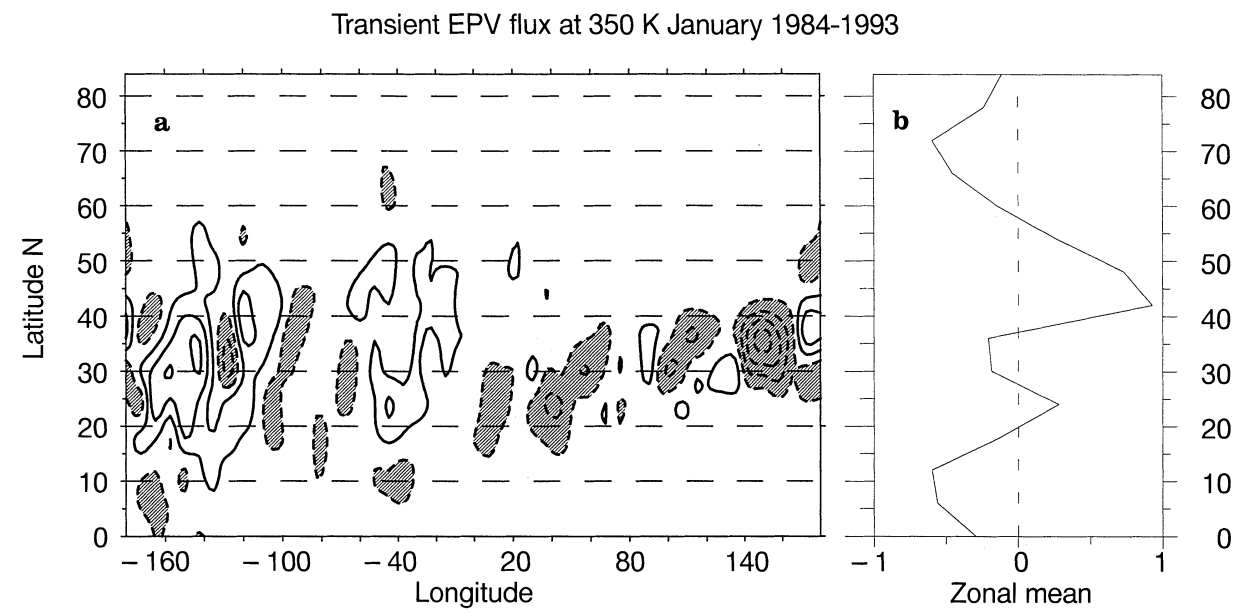

Fig. 14a, b. Climatological meridional transient eddy PV flux in $10^{-5} \mathrm{~m} \mathrm{~s}^{-2}$ at a the $350-\mathrm{K}$ surface and $\mathbf{b}$ its zonal average in northern hemisphere January based on 10 years of ECMWF analysis 1984-1993. The contour interval is 6 . Regions with values below -3 are shaded and the contours are dashed
Comparison of our $K_{y y}$ derived from ECMWF analysis and from ECHAM3 experiments gives an estimate of the model efficiency with respect to zonally averaged transient eddy transport. As discussed in Sect. 4.4, considerable deviations between the PV flux from both data sources in some seasons in the troposphere do not result in a qualitatively different $K_{y y}$ pattern. This shows the robustness of the significant parts of the mixing pattern already discussed.

The most striking difference is the occurrence of positive PV flux regions immediately polewards of the jet not only in winter but in all seasons and also in the $\mathrm{SH}$. In the $\mathrm{SH}$ the most obvious difference between ECMWF analysis and model consists in a maximum zonal wind speed in the subtropical jet in the model which is about $10 \mathrm{~m} \mathrm{~s}^{-1}$ greater than in the analysis. The stronger positive PV fluxes by modification of the uppertropospheric and lower-stratospheric wind shear in a GCM are not fully understood.

Climatological mean meridional circulation for the troposphere calculated in this work based on 10 years of analysis has to be compared with the four seasonal means calculated by Townsend and Johnson (1985) from the FGGE data set covering a 12-month period in 1978-1979. It turns out that both results are in qualitative agreement with respect to seasons, branch structure and order of magnitude. Especially the tropospheric part of circulation, Fig. 2, also agrees quantitatively with the result of Townsend and Johnson (1985). Considered in more detail, we find excellent agreement of the circulation strength in the SH tropical (Hadley) branch of the hemispheric cell throughout the year and differences in the extratropical branch, which is weaker in our analysis in the $\mathrm{NH}$ and stronger in the $\mathrm{SH}$. The difference between $\mathrm{SH}$ winter (summer) and $\mathrm{NH}$ winter (summer) Hadley branch is much smaller in our 10-year data set. Note that a similar meridional transport streamfunction can be obtained by averaging in density coordinates (Karoly et al., 1997).

In the ECHAM3-T21-experiments meridional mass flow rate, $V_{d}$, in subtropics is seriously wrong in strength and direction above $390 \mathrm{~K}$ (Fig. 5a) in comparison with the mean ECMWF circulation. This can not be a consequence of the upper boundary condition at $500 \mathrm{~K}$ $(\bar{W}=0)$, because $V_{d}$ is derived directly from Eq. (4) in both cases. The strength of deviation depends on the model spectral resolution. This can be seen in Fig. 15, where the result of the T42 experiment is shown. Comparison with the T21 result in Fig. 5a yields that the subtropical circulation in the lower stratosphere has opposite direction. That may be caused by the treatment of the layers above $100 \mathrm{hPa}$ with a large hyperdiffusion. On the other hand the tropospheric circulation is similar. The difference of $V_{d}$ between the T21 and T42 runs means that the T21 circulation is not sufficient as a mean transport circulation in a 2D model. But we have the possibility to calculate the mean meridional circulation from the physical model heating rates. In this way we obtain a realistic transport circulation with the only drawback that consistency with $K_{y y}$ is lost in the lower stratosphere.

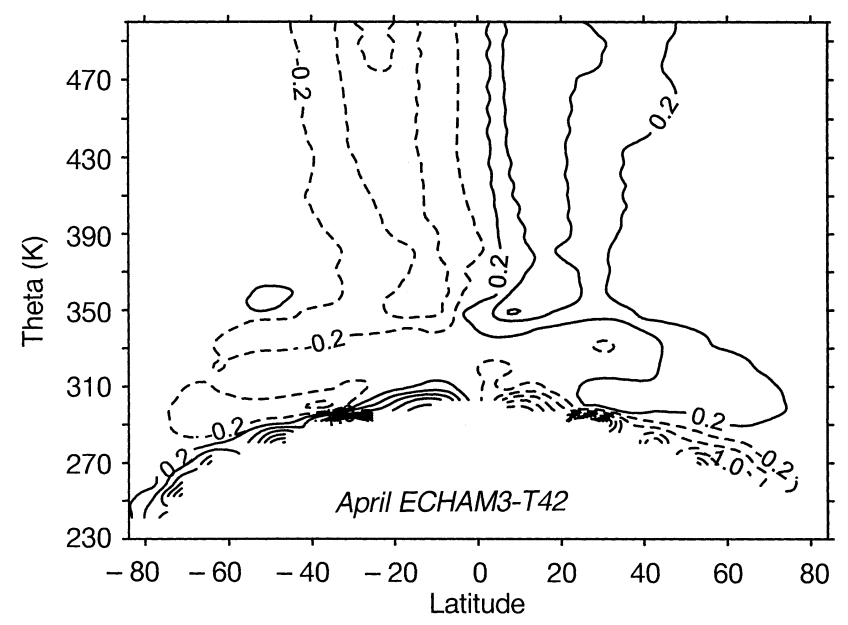

Fig. 15. Isentropic mean meridional mass flow rate $\bar{V}_{d} / \bar{\rho}_{\Theta}$ for April from ECHAM3-T42. The contour interval is 0.4 and negative contours are dashed 


\section{Summary and conclusions}

Two sets of climatological seasonal transport parameters are presented for possible application in zonally averaged transport models of the troposphere and lower stratosphere. The data base comprises 10 years of ECMWF analysis and of ECHAM3 GCM runs. Calculation is based on the isentropic parameterization formalism of Tung (1986).

Our mean meridional mass circulation derived from 10 years of ECMWF analysis is the climatological update of the isentropic analysis of Townsend and Johnson (1985) for a 12-month period. Good agreement is found in shape and strength of the direct hemispheric circulation cells in the troposphere. The most striking quantitative change is the reduced difference of the circulation strength between the northern hemisphere in January and southern hemisphere in July.

Parameterization of large-scale eddy mixing along isentropes in the troposphere and lower stratosphere is done consistently with the mean meridional circulation based on 3D data and a flux-gradient relation. The spatial structure of isentropic mixing has a connection with the temporal and spatial evolution of baroclinic disturbances. Regions with more efficient horizontal mixing are found (1) in a vertical band in the subtropics and (2) in mid-latitudes in the middle troposphere, especially in winter and spring, when the maximum of negative PV flux is clearly below the tropopause. In NH winter and spring strong evidence is found that baroclinic-wave development is determined by the stationary wave structure, resulting in an enhanced positive PV flux in a small region polewards of the subtropical jet. Immediately above the $\mathrm{NH}$ mid-latitude tropopause zonally averaged PV flux is the result of incomplete cancellation of much stronger regional fluxes with opposite sign. A strong interannual variability of the net zonally averaged flux is observed. This is a consequence of the situation that the result of cancellation of large quantities is sensible to fluctuations of the ground state.

A climatological tropospheric zonal mean barrier for large-scale eddy mixing is detected in the ECMWFanalysis data set in winter and spring in both hemispheres. Its latitudinal position coincides with the position of the subtropic jet.

Comparison of the ECHAM3 mass circulation with the ECMWF-analysis result yields that tropospheric circulation is similar in most aspects if it is calculated from the diabatic heating rates of the model equations. Model meridional mass flow rate in the subtropics above $100 \mathrm{hPa}$ differs significantly from the analysis. Sign and value of the deviation depend on model spectral resolution, suggesting that it is determined by the numerical treatment of the upper boundary in the model. Qualitative shape of the $K_{y y}$ pattern, its seasonal cycle and correlation with the zonally averaged zonal wind observed in the analysis data are reproduced to a large extent by the model. Reduced interannual variability in the model experiments improves statistical significance of this mixing pattern. Major differences occur polewards of the subtropical jets, where positive PV flux is more frequent and stronger in the model.

The verification of Tung's parameterization formalism for the troposphere and lower stratosphere by this work contribute towards a uniform description of zonally averaged transport in troposphere and stratosphere.

Acknowledgements. We thank the German Weather Service in Offenbach for the opportunity to utilize ECMWF-analysis data and the German Climate Computing Centre in Hamburg for providing the ECHAM3-T42 experiments and consultations supporting our own experiments. We thank Dr. K.-M. Greisiger for his support in ECMWF analysis data processing. This work was supported by the German Science Foundation.

Topical Editor F. Vial thanks K. K. Tung and D. Karoly for their help in evaluating this paper.

\section{References}

AMIP I, The atmospheric model intercomparison project, PCMDI Rep. No. 7, 1995 (also in Bull. Am. Meteorol. Soc., 73, 1962; or http://www-pcmdi.llnl.gov/AMIPtoc.html).

Andrews, D. G., A finite-amplitude Eliassen-Palm theorem in isentropic coordinates, J. Atmos. Sci., 40, 1877, 1983.

Andrews, D. G., and M. E. McIntyre, Planetary waves in horizontal and vertical shear: the generalized Eliassen-Palm relation and the zonal mean acceleration, J. Atmos. Sci., 33, 2031, 1976.

Chen, P., Isentropic cross tropopause mass exchange in the extratropics, J. Geophys. Res., 100, 16661, 1995.

Edmon, H. J., Jr., B. J. Hoskins, and M. E. McIntyre, EliassenPalm cross sections for the troposphere, J. Atmos. Sci., 36, 2600, 1980.

Garcia, R. R., Parameterization of planetary wave breaking in the middle atmosphere, J. Atmos. Sci., 48, 1405, 1991.

GCCC, The ECHAM3 atmospheric general circulation model, German climate computing centre, Hamburg, Tech. Rep. 6, 1993.

James, I. N., Introduction to circulating atmospheres, Cambridge University Press, Cambridge, 1994.

Juckes, M. N., A shallow water model of the winter stratosphere, J. Atmos. Sci., 46, 2934, 1989.

Juckes, M. N., I. N. James, and M. Blackburn, The influence of Antarctica on the momentum budget of the southern extratropics, Q. J. R. Meteorol. Soc., 120, 1017, 1994.

Karoly, D. J., Eliassen-Palm cross sections for the northern and southern hemispheres, J. Atmos. Sci., 39, 178, 1982.

Karoly, D. J., P. C. McIntosh, P. Berrisford, T. J. McDougall and A. C. Hirst, Similarities of the Deacon cell in the Southern Ocean and Ferrel cells in the atmosphere, Q.J.R. Meteorol. Soc., 123, 519, 1997.

Lau, N.-C., The structure and energetics of transient disturbances in the Northern Hemisphere wintertime circulation, J. Atmos. Sci., 36, 982, 1979.

Lorenz, E. N., Available potential energy and the maintenance of the general circulation, Tellus, 7, 157, 1955.

McIntyre, M. E., and T. N. Palmer, Breaking planetary waves in the stratosphere, Nature, 305, 593, 1983.

McIntyre, M. E., and T. N. Palmer, The 'surf zone' in the stratosphere, J. Atmos. Terr. Phys., 46, 825, 1984.

Nakamura, M., and R. A. Plumb, The effects of flow asymmetry on the direction of Rossby wave breaking, J. Atmos. Sci., 51, 2031, 1994.

Newman, P. A., M. R. Schoeberl, R. A. Plumb, and J. E. Rosenfield, Mixing rates calculated from potential vorticity, J. Geophys. Res., 93, 5221, 1988.

Pierrehumbert, R. T., and H. Yang, Global chaotic mixing in isentropic surfaces, J. Atmos. Sci., 44, 298, 1993. 
Plumb, R. A., Eddy fluxes of conserved quantities by smallamplitude waves, J. Atmos. Sci., 36, 1699, 1979.

Plumb, R. A., and J. D. Mahlmann, The zonally averaged transport characteristics of the GFDL general circulation/transport model, J. Atmos. Sci., 44, 298, 1987.

Prather, M. J., and E. E. Remsberg, The atmospheric effects of stratospheric aircraft: report of the 1992 models and measurements workshop, vol. III - special diagnostic studies, NASA RP-1292, 1993.

Pyle, J. A., and C. F. Rogers, Stratospheric transport by stationary planetary waves - the importance of chemical processes, $Q . J$. R. Meteorol. Soc., 106, 421, 1980.

Randel, W. J., Coherent wave-zonal mean flow interaction in the troposphere, J. Atmos. Sci., 47, 439, 1990.

Randel, W. J., and R. R. Garcia, Application of a planetary wave breaking parameterization to stratospheric circulation statistics, J. Atmos. Sci., 51, 1157, 1994.

Roeckner, E., K. Arpe, L. Bengtsson, S.Brinkop, L. Dümenil, M. Esch, E. Kirk, F. Lunkeit, M.Ponater, B. Rockel, R. Sausen, U. Schlese, S. Schubert, and M. Windelband, Simulation of the present-day climate with the ECHAM model: impact of model physics and resolution, MPI Report No. 93, Hamburg, 1992.
Sassi, F., G. Visconti, and J. C. Gille, Validation of parameterization scheme for eddy diffusion from satellite data, J. Atmos. Sci., 47, 2505, 1990.

Schmitz, G., and K. Dethloff, Interpretation of quasi-geostrophic potential vorticity fluxes on the basis of climatological data, Z. Meteorol., 34, 159, 1984.

Thorncroft, C. D., B. J. Hoskins, and M. E. McIntyre, Two paradigms of baroclinic-wave life-cycle behaviour, $Q . J . R$. Meteorol. Soc., 119, 17, 1993.

Townsend, R. D., and D. R. Johnson, A diagnostic study of the isentropic zonally averaged mass circulation during the first GARP global experiment, J. Atmos. Sci., 42, 1565, 1985.

Tung, K. K., On the two-dimensional transport of stratospheric trace gases in isentropic coordinates, J. Atmos. Sci., 39, 2330, 1982.

Tung, K. K., Nongeostrophic theory of zonally averaged circulation. Part I: Formulation, J. Atmos. Sci., 43, 2600, 1986.

WMO, Scientific assessment of ozone depletion: 1994, WMO 37, Geneva, 1995.

Yang, H., K. K. Tung, and E. Olaguer, Nongeostrophic theory of zonally averaged circulation. Part II: Eliassen-Palm-flux divergence and isentropic mixing coefficient, J. Atmos. Sci., 47, 215, 1990. 